\title{
Characterization of a Multistage Continuous MSMPR Crystallization Process assisted by Image Analysis of Elongated Crystals
}

Capellades, Gerard; Joshi, Parth U.; Dam-Johansen, Kim; Mealy, Michael J.; Christensen, Troels V.; Kiil, Søren

\section{Published in:}

Crystal Growth \& Design

Link to article, DOI:

10.1021/acs.cgd.8b00446

Publication date:

2018

Document Version

Peer reviewed version

Link back to DTU Orbit

Citation (APA):

Capellades, G., Joshi, P. U., Dam-Johansen, K., Mealy, M. J., Christensen, T. V., \& Kiil, S. (2018).

Characterization of a Multistage Continuous MSMPR Crystallization Process assisted by Image Analysis of

Elongated Crystals. Crystal Growth \& Design, 18(11), 6455-6469. https://doi.org/10.1021/acs.cgd.8b00446

\section{General rights}

Copyright and moral rights for the publications made accessible in the public portal are retained by the authors and/or other copyright owners and it is a condition of accessing publications that users recognise and abide by the legal requirements associated with these rights.

- Users may download and print one copy of any publication from the public portal for the purpose of private study or research.

- You may not further distribute the material or use it for any profit-making activity or commercial gain

- You may freely distribute the URL identifying the publication in the public portal 


\section{Article}

\section{Characterization of a Multistage Continuous MSMPR Crystallization Process assisted by Image Analysis of Elongated Crystals}

Gerard Capellades, Parth U. Joshi, Kim Dam-Johansen, Michael J. Mealy, Troels V. Christensen, and Søren Kiil

Cryst. Growth Des., Just Accepted Manuscript • DOI: 10.1021/acs.cgd.8b00446 • Publication Date (Web): 05 Oct 2018

Downloaded from http://pubs.acs.org on October 8, 2018

\section{Just Accepted}

"Just Accepted" manuscripts have been peer-reviewed and accepted for publication. They are posted online prior to technical editing, formatting for publication and author proofing. The American Chemical Society provides "Just Accepted" as a service to the research community to expedite the dissemination of scientific material as soon as possible after acceptance. "Just Accepted" manuscripts appear in full in PDF format accompanied by an HTML abstract. "Just Accepted" manuscripts have been fully peer reviewed, but should not be considered the official version of record. They are citable by the Digital Object Identifier (DOI@). "Just Accepted" is an optional service offered to authors. Therefore, the "Just Accepted" Web site may not include all articles that will be published in the journal. After a manuscript is technically edited and formatted, it will be removed from the "Just Accepted" Web site and published as an ASAP article. Note that technical editing may introduce minor changes to the manuscript text and/or graphics which could affect content, and all legal disclaimers and ethical guidelines that apply to the journal pertain. ACS cannot be held responsible for errors or consequences arising from the use of information contained in these "Just Accepted" manuscripts. 
Characterization of a multistage continuous MSMPR crystallization process assisted by image analysis of elongated crystals

Gerard Capellades, ${ }^{\dagger} \ddagger$ Parth U. Joshi, ${ }^{\dagger}$ Kim Dam-Johansen, ${ }^{\dagger}$ Michael J. Mealy, ${ }^{\ddagger}$ Troels V. Christensen $*$ and Søren Kiil ${ }^{*}, \dagger$

$\uparrow$ Department of Chemical and Biochemical Engineering, Technical University of Denmark, DTU, Building 229, 2800 Kgs. Lyngby, Denmark

†. Lundbeck A/S, Oddenvej 182, 4500 Nykøbing Sjælland, Denmark

This paper provides a proof-of-concept for the application of quantitative image analysis to modern methods for the optimization of MSMPR crystallizers. The work includes continuous crystallization of Melitracen $\mathrm{HCl}$, a tricyclic antidepressant that often presents elongated crystals. As it occurs in full-scale production, the API crystals tend to break during downstream processing, leading to a change in particle shape. In this work, the use of quantitative image analysis allowed to optimize an MSMPR cascade to produce crystals of the adequate crystal width and height, thus adjusting the most consistent dimensions to the formulation requirements. While other size measurement methods depend on crystal shape, the volumetric crystal width and height distributions do not vary with a small extent of crystal breakage. The measured crystal size distributions are thus representative for the early assessment of crystal quality, without the need of complex breakage modelling in downstream production.

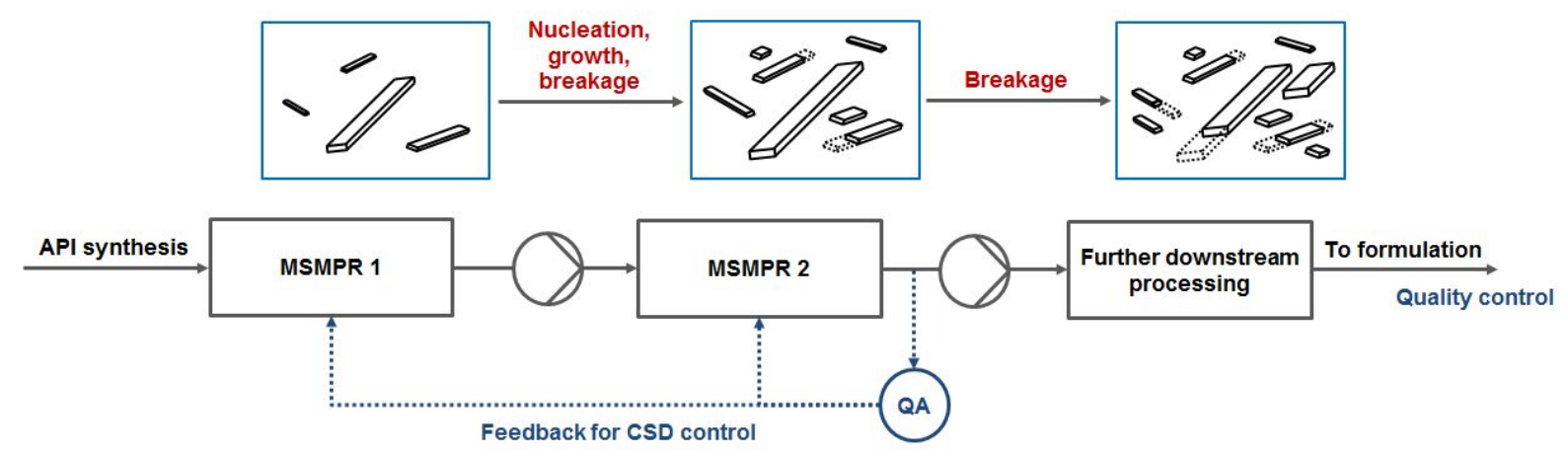

\section{Søren Kiil}

Søltofts Plads, Building 229

2800 Kgs. Lyngby

Denmark
Phone +4545252827

Email sk@kt.dtu.dk

www.kt.dtu.dk 


\title{
Characterization of a Multistage Continuous
}

\section{MSMPR Crystallization Process assisted by Image Analysis of Elongated Crystals}

\author{
Gerard Capellades, ${ }^{\dagger,+}$ Parth U. Joshi, ${ }^{\dagger}$ Kim Dam-Johansen, ${ }^{\dagger}$ Michael J. Mealy,,+ Troels V. \\ Christensen $^{+}$and Søren Kiil*, ${ }^{*}$ \\ $†$ Department of Chemical and Biochemical Engineering, Technical University of Denmark, \\ DTU, Building 229, 2800 Kgs. Lyngby, Denmark
}

† H. Lundbeck A/S, Oddenvej 182, 4500 Nykøbing Sjælland, Denmark

Corresponding author e-mail: $\underline{\mathrm{sk} @ \mathrm{kt} . \mathrm{dtu} . \mathrm{dk}}$.

\begin{abstract}
This work demonstrates how quantitative image analysis can assist in the characterization of continuous crystallization processes and in the proper selection of mathematical models for the early assessment of crystal quality. An active pharmaceutical ingredient presenting an elongated crystal habit has been crystallized using two stirred tank crystallizers in series. Using image analysis of the crystallization magma, the sources of crystal breakage in the crystallization cascade have been identified and the impact on crystal habit has been evaluated quantitatively. As it is expected for particles presenting high aspect ratios, crystal breakage preferentially occurs in the smallest plane, perpendicular to the largest dimension. This phenomenon is hardly avoidable in downstream production, but it can be accounted with a design approach based on
\end{abstract}


the real crystal dimensions. The kinetic rate equations for nucleation and crystal growth have been determined based on crystal width, from which a model for the accurate prediction of this dimension has been applied. The predicted crystal size distribution is consistent through a moderate degree of crystal breakage during downstream processing.

\section{INTRODUCTION}

In recent years, transition from batch to continuous production has received a significant interest in the pharmaceutical industry. Due to the increasing costs of drug development and the competition from generic manufacturers, extensive research has been conducted for the development of continuous processes for the cost effective manufacturing of pharmaceuticals with consistent quality. ${ }^{1-3}$

Crystallization plays an important role in pharmaceutical production, both as a purification method and as a tool to produce crystals of active pharmaceutical ingredients (APIs) with the right size, habit and crystal structure. ${ }^{4}$ Mixed suspension mixed product removal (MSMPR) crystallizers are arguably the most common choice of system for continuous pharmaceutical crystallization. Normally in the form of stirred tanks, these crystallizers are simple, versatile, and suitable for the in-line assessment of product quality. In contrast with plug flow crystallizers, MSMPR crystallizers are preferred for handling the concentrated suspensions and for the long residence times that are characteristic of crystallization processes.

Previous work demonstrated the applicability of MSMPR crystallizers for continuous production of well-known small molecule pharmaceuticals including cyclosporine, ${ }^{5-7}$ deferasirox, ${ }^{8}$ aliskiren hemifumarate ${ }^{9}$ and acetaminophen, ${ }^{10,11}$ among others. The development focus depends on the actual demands for the crystallization process, and it becomes particularly 
challenging for compounds showing polymorphism and complex impurity compositions in the feed stream. ${ }^{12-14}$ In the field of crystal size distribution control, a common approach is to use semi-empirical rate equations combined with the mass and population balance in the crystallizer to predict the resulting yield and size distribution from a given set of process conditions. Such models offer a significant advantage for the assessment of the attainable crystal sizes and facilitate the selection of an optimal number of stages for the crystallization process. ${ }^{11,15}$

Size characterization techniques are typically based on laser diffraction, sieve fractions or chord length distributions. These techniques, despite being sensitive to the shape of the crystals, offer a size distribution that is based on a single characteristic dimension and thus provide little to no information on the crystal shape. In recent years, a number of methods have been developed for process imaging that have potential for simultaneous in-line control of the crystal size and shape during crystallization. ${ }^{16,17}$ Probe-based instruments like Mettler Toledo's Particle Vision and Measurement (PVM) system are frequently used for the qualitative evaluation of crystal shapes during crystallization. ${ }^{10,18-27}$ Furthermore, the development of alternative noninvasive methods is often reported. These methods involve external high-speed cameras that are either directed to a measurement window in the crystallizer ${ }^{28-31}$ or to an external sampling loop. ${ }^{32-34}$

Image analysis allows for the application of morphological population balances to crystallization. Tracking size distributions in multiple dimensions can provide several advantages for the characterization of crystallization processes, not only for the application of multidimensional crystal size prediction models, but also for the detection of phenomena like agglomeration, crystal breakage, growth rate dispersion or transitions in crystal shape. ${ }^{35,36}$ Despite the advantages of image analysis for characterization of crystallization processes and 
their increasing use in batch crystallization, optimization of an MSMPR crystallizer is rarely conducted for crystal size distributions based on quantitative image analysis, and only few examples can be found in the literature. ${ }^{37-39}$ In this work, an MSMPR crystallization cascade has been characterized by analyzing the $2 \mathrm{D}$ projection of the steady state magma. The effect of process conditions on crystal shape has been evaluated, and the source and extent of crystal breakage have been studied quantitatively. Following the determination of the kinetic rate equations from population and mass balance modelling, the attainable particle sizes in the cascade have been determined based on the crystal dimensions that will be retained in the formulation product.

\section{MOTIVATION AND HYPOTHESIS}

Elongated crystals, typically in the shape of needles or plates, are very common in pharmaceutical production, with products like salicylic acid, acetaminophen or aliskiren hemifumarate often presenting this type of crystal habit. ${ }^{9,40,41}$ These crystals are some of the hardest to characterize since most of the size determination techniques assume spherical particles. Furthermore, elongated crystals tend to be fragile in their largest dimension, and it is not uncommon that the shape of the crystallization product differs significantly from that at the formulation step. Figure 1 shows a typical approach for in-line size distribution control in a two stage continuous MSMPR process dealing with plate crystals, and a hypothesis on how the crystal shape will evolve through mechanical stress during crystallization and downstream processing. 

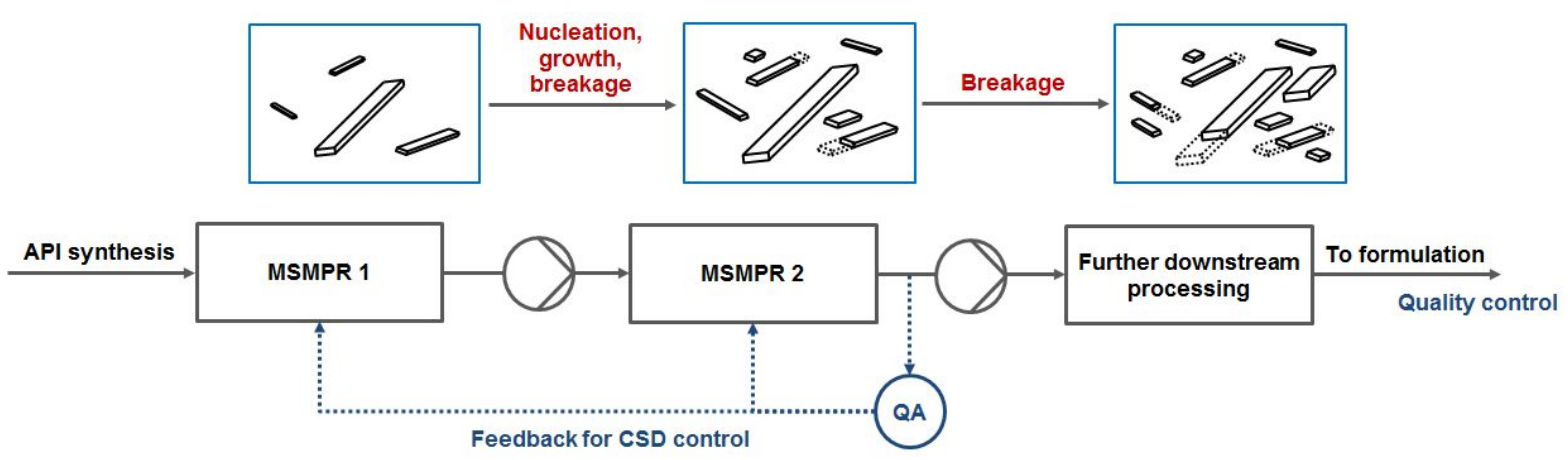

Figure 1. Hypothetical crystal breakage during suspension transfer and downstream processing of elongated plate crystals. Quality assurance (QA) is expected to occur at the end of the crystallization process, providing feedback for crystal size distribution (CSD) control in the MSMPR cascade.

The crystal size distribution can be expressed in at least as many ways as the number of dimensions defining the crystal habit. Assuming that the crystals are perfect plates, we can distinguish between crystal length, width and height in order of decreasing size. Systems that exhibit preferential breakage in a single plane have a peculiarity: ideally, only the volumetric crystal size distribution based on the perpendicular dimension will be affected by breakage, as the total mass related to each of the other crystal dimensions is retained during crystal fracture. This hypothesis assumes that crystal breakage occurs in a plane that is completely perpendicular to the largest dimension, and neglects the formation of fines during the fracture. Thus, it works best for systems with high aspect ratios and a limited degree of crystal breakage.

For systems following this behavior, the mathematical modelling of the MSMPR crystallizer can be simplified by use of a crystal shape that is only dependent on the crystallization rate. This distribution permits the determination of a population function that is independent of crystal breakage, thus allowing the independent evaluation of mechanisms like size-dependent growth or growth rate dispersion. Then, a crystal size prediction model can be developed for those 
dimensions that are consistent through downstream processing. The formulation 3D crystal size distribution can be approximated from the predicted dimension and the distribution of aspect ratios obtained after downstream processing, thus simplifying the extensive breakage modelling in downstream processing.

\section{MATERIALS AND METHODS}

Materials. Melitracen hydrochloride ( $\geq 99.8 \%$ purity) was obtained in powder form from fullscale batch production in $\mathrm{H}$. Lundbeck A/S. Absolute ethanol ( $\geq 99.8 \%$ purity) was purchased from VWR Chemicals and used as a solvent for the process. Acetone ( $\geq 99.5 \%$ purity) purchased from VWR Chemicals was used to wash the crystals after filtration.

Experimental setup. A schematic diagram of the continuous crystallization setup is depicted in Figure 2. The setup consists of three vessels connected with programmable peristaltic pumps (P1: LongerPump BT100-1F; P2/P3: LongerPump WT600-1F), and it can operate both for single stage and two stage continuous crystallization. P1 continuously delivered the feed solution to the first MSMPR crystallizer at a flow rate between 1.8 and $7.3 \mathrm{~mL} / \mathrm{min}$, depending on the residence time. To prevent crystallization in the feed tubing, the stream was heat traced to $60{ }^{\circ} \mathrm{C}$ using heat tape and a temperature control unit (Lund \& Sørensen). The product removal streams were not heat traced. 


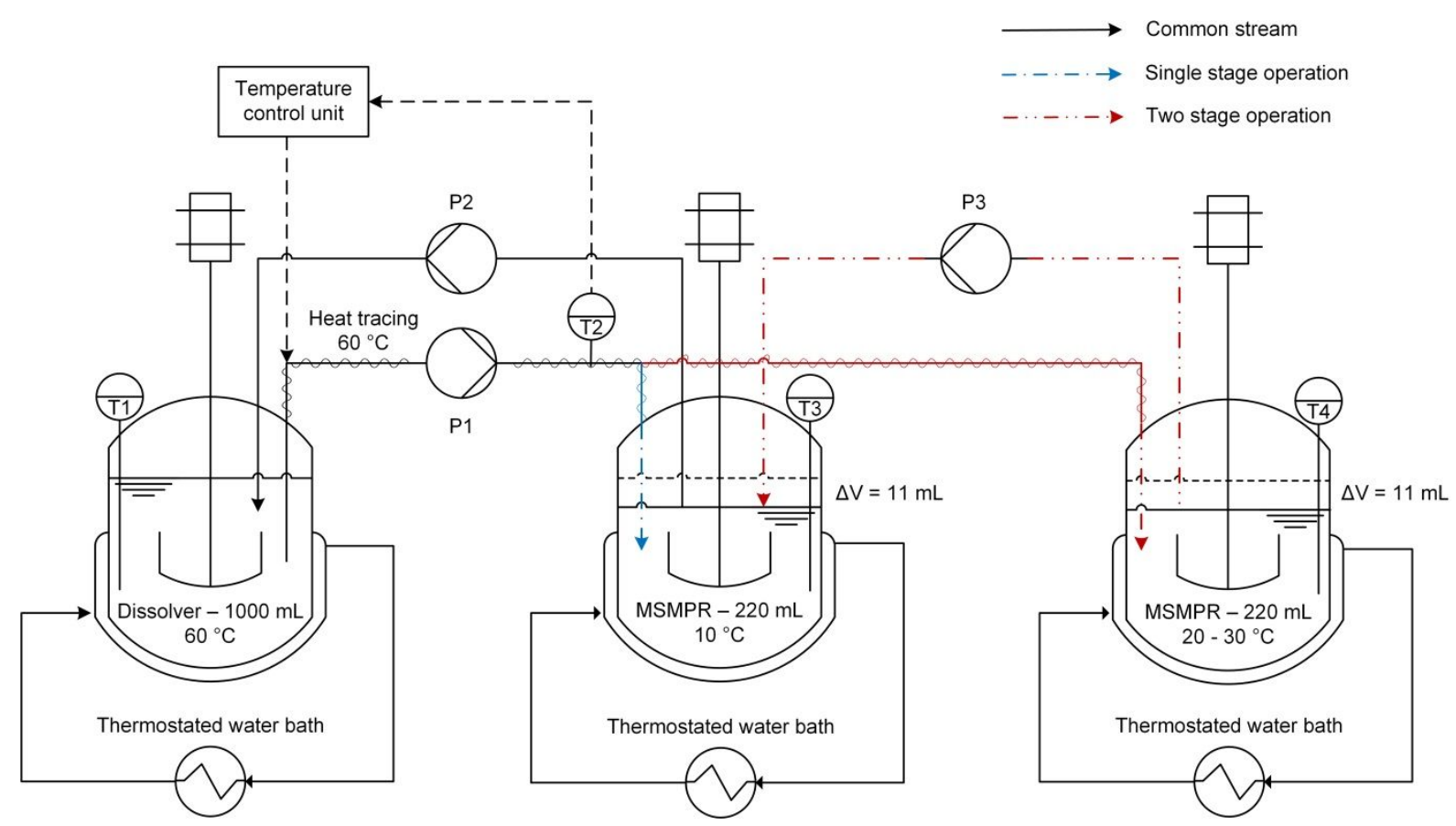

Figure 2. Schematic diagram of the two stage MSMPR crystallization setup.

Two jacketed round-bottom reactors with mechanical stirring and an operating volume of 220 $\mathrm{mL}$ were used as MSMPR crystallizers. The crystallization magma was mechanically agitated using a three-blade ringed propeller $(45 \mathrm{~mm}$, stainless steel, Heidolph Instruments) working at $400 \mathrm{rpm}$. Due to the nature of the crystallization system, the impellers were coated with a thermoplastic fluoropolymer (Accofal 2G54, Accoat) to prevent fouling and corrosion during extended operation times. Both crystallizers were constructed with the same components, and they operated with the same volume and agitation speed.

Following a common approach for the operation of lab-scale MSMPR crystallizers, suspension transfer was conducted in semi-continuous mode to achieve isokinetic withdrawal of the crystallization magma. ${ }^{5,10,42} \mathrm{P} 2$ and $\mathrm{P} 3$ were programmed to operate intermittently, removing 5\% of the suspension volume every $5 \%$ of a residence time. For a maximum suspension density of 
$100 \mathrm{~g} / \mathrm{L}$, a flow rate of $1850 \mathrm{~mL} / \mathrm{min}$ and a tubing internal diameter of $6.4 \mathrm{~mm}$ were sufficient to prevent both classification and plugging during suspension transfer.

To be able to operate for extended periods of time and to minimize the amount of feed solution required for an experiment, the crystallization magma was returned to the feed vessel so that the product could be re-dissolved and reused as feed. ${ }^{11}$ For a feed temperature of $60{ }^{\circ} \mathrm{C}$ and diluting $11 \mathrm{~mL}$ of magma in $1000 \mathrm{~mL}$ of undersaturated solution on each cycle, it required only few seconds for the magma to completely dissolve. The heat tracing in the feed pipe ensures that any remaining fines were dissolved before reaching the first crystallizer.

Determination of the solubility curve. The first step in the experimental section was to determine a solubility curve for the crystallization system. A $220 \mathrm{~mL}$ suspension containing 125 $\mathrm{g} / \mathrm{L}$ of API was prepared in the MSMPR crystallizer at room temperature. After crash cooling to $5{ }^{\circ} \mathrm{C}$, the suspension was maintained under agitation for $2.5 \mathrm{~h}$. Then, triplicate $4 \mathrm{~mL}$ samples of the suspension were filtered through a $0.45 \mu \mathrm{m}$ sterile syringe filter and the liquid phase was kept for high-performance liquid chromatography (HPLC) analysis. To verify that the system was at equilibrium, samples were removed in 10 min intervals and the concentrations were compared. Further solubility points were obtained applying heating intervals of $5{ }^{\circ} \mathrm{C}$ to the same suspension. After each objective temperature was reached, the suspension was kept agitated for $90 \mathrm{~min}$ prior to the removal of triplicate samples. A total of 7 solubility points were obtained within the range of 5 to $35^{\circ} \mathrm{C}$.

Operation of the MSMPR cascade. The continuous crystallization experiments were conducted in the setup described in Figure 2. Before each experiment, the feed vessel and the crystallizers were filled with solvent and API to the target feed concentration. This was done at room temperature. Then, the temperatures of each vessel were adjusted to the experimental 
conditions. The pumps were started as soon as the temperatures stabilized. P1 was set to pump at full speed for the first $10 \mathrm{~s}$ of operation to equilibrate the temperature throughout the feed stream and prevent clogging during start-up. Then, the calibration of the flow rate was validated using a $5 \mathrm{~mL}$ graduated cylinder.

The evolution to steady state was tracked in-line using an FBRM ParticleTrack G400 probe from Mettler Toledo. To obtain relevant chord length distribution data, the probe window was cleaned every residence time to remove encrustation. The onset of steady state was determined from FBRM data and later verified by HPLC determination of the system concentrations. For the experiments in this work, the MSMPR crystallizers were able to operate to steady state with negligible encrustation in the vessel wall or the impellers.

The steady state was sustained for at least four consecutive residence times before the experiment was stopped. At each residence time, $4 \mathrm{~mL}$ samples were removed from the feed solution and the crystallization mother liquor. The mother liquor samples were obtained by filtration of a magma sample through a $0.45 \mu \mathrm{m}$ syringe filter.

After the steady state sampling, the feed flow rate was measured again to verify that the residence time was not altered during the experiment. The acceptance criterion was a deviation in the feed flow rate equal to or lower than $0.1 \mathrm{~mL} / \mathrm{min}$ between the start and the end of the experiment. Then, three samples of the crystallization magma were collected at three different positions in the crystallizer (top, middle, and bottom). The steady state classification in the MSMPR unit was assessed from the mass balance, evaluating the difference between the total API concentration in the magma samples and that in the feed vessel. At the end of an experiment, the crystallization magma was filtered using a vacuum system and the crystals were washed with cold acetone. Although no issues with polymorphism have been previously 
experienced for this compound in batch production, samples from four relevant experiments were analyzed using X-ray powder diffraction (XRPD) to verify that the crystal structure remained consistent throughout this work. The obtained classification levels and XRPD patterns are reported in supporting information.

Off-line analytical techniques. The solubility, feed, mother liquor and magma samples were analyzed using HPLC. The HPLC system (Hitachi LaChrom Elite) was equipped with a Phenomenex Gemini ${ }^{\circledR} 10 \mathrm{~cm}$ x $4.6 \mathrm{~mm}$ x $3 \mu \mathrm{m} \mathrm{C18} 110 \AA$ silica column and a L-2455 diode array detector (Hitachi). The API concentrations were determined at $230 \mathrm{~nm}$. XRPD patterns of the filtered crystals were obtained for $2 \theta$ between $5^{\circ}$ and $40^{\circ}$ using a Bruker D8 Advance diffractometer. Finally, SEM analysis was conducted to determine the 3D shape of the crystals employing a FEI Quanta 200 electron microscope. The SEM samples were pre-coated with a 5$10 \mathrm{~nm}$ gold layer.

Image analysis. A simple off-line sampling method for the accurate imaging of the crystallization magma has been developed in this work. It was decided to aim for a labor intensive yet reliable method to determine the crystal size distributions. A major limitation for in-situ image analysis is the ability to provide quantitative results at high solid concentrations. In addition, determination of the 2D or 3D crystal shape from pictures obtained with an in-line camera is complicated. The observed crystal size is a function of the crystal orientation as well as their distance to the focal point. Since variations in the steady state crystal size distribution from MSMPR crystallization can sometimes be very small, an off-line method where the crystals fall flat in the same plane was employed.

The method consists of diluting a sample of the crystallization magma with a saturated solution of the solute and then measuring the crystal dimensions in a closed system. To prepare the 
saturated solution, Melitracen $\mathrm{HCl}$ powder was suspended in ethanol a day beforehand and left agitated at room temperature during the experiment. Before withdrawing a sample from the MSMPR magma, the prepared suspension was filtered using two $0.45 \mu \mathrm{m}$ syringe filters in series, collecting the liquid phase in an open petri dish (approximated capacity: $20 \mathrm{~mL}$ ). The petri dish was completely filled to minimize the amount of air trapped in the sample. Then, a few drops of the MSMPR magma were added to the saturated solution using a transfer pipette, and the petri dish was immediately sealed.

This sampling approach has multiple advantages. First, the saturated API solution dilutes the sample, thereby bringing the supersaturation in the magma down to a negligible value. This limits crystal growth during off-line analysis. In addition, diluting the sample in the saturated solution greatly reduces the suspension density, allowing for an easier identification of each crystal in the picture and reducing the amount of overlapping crystals. Using a closed petri dish minimizes solvent evaporation, which would otherwise promote crystal growth. Lastly, analyzing a suspended sample facilitates the even distribution of the fragile crystals by gentle shaking, and allows to differentiate agglomerates from overlapped crystals.

The samples were analyzed using a Nikon Eclipse ME600 optical microscope equipped with an HD camera (Leica MC120) and the Leica Application Suite software (ver. 4.5). To verify the stability of the crystal size distribution during the off-line sampling, pictures were taken at the same position immediately after sample preparation and 5 minutes later to detect dissolution and crystal growth. Figure 3 shows an example of two pictures taken for this verification method. After the sample stability was verified, the petri dish was screened to obtain representative pictures of the crystallization magma. At this point, all the crystals have settled and the crystal size distribution is consistent over time. 

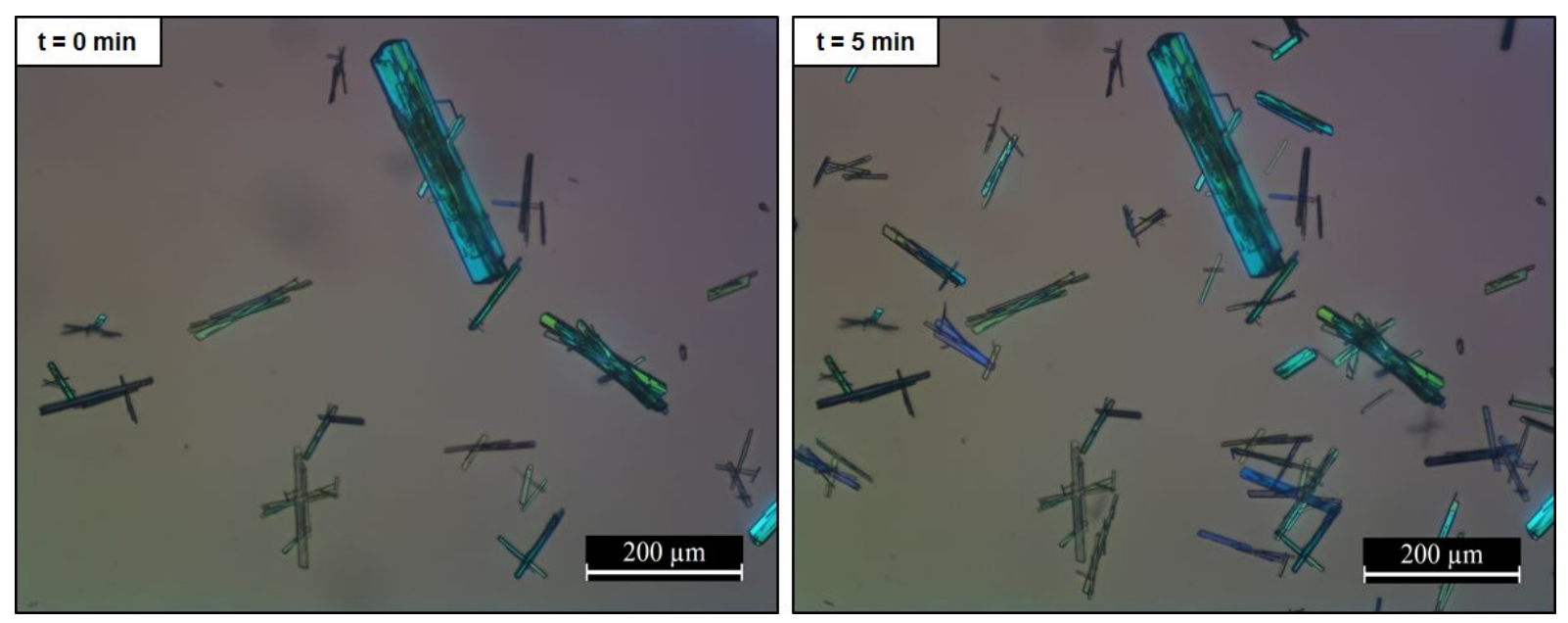

Figure 3. Off-line optical microscopy pictures of the crystallization magma, taken at the same position in the petri dish. The pictures are taken 5 minutes apart to study the stability of the offline samples. The second picture contains more crystals as the suspension takes 2-3 minutes to settle completely.

Note that this off-line sampling method is not as practical as the state of the art in-line process imaging, from which magma pictures can be obtained in real time using a non-invasive instrument. The main disadvantage of the method described here is that it is limited to process design, and off-line sampling is not a practical approach for crystal shape control in the full-scale process. However, with the recent advancements in the development of algorithms for the accurate determination of crystal size and shape from on-line process imaging, this process will likely be automated soon. ${ }^{30-32,43}$

Image analysis was conducted manually using the image processing software ImageJ (ver. 1.6.0). This software was used as a tool to zoom into the analyzed pictures and to record the measured dimensions. The measurements originated from several pictures obtained at four different residence times in the steady state crystallizer. Because the crystallization magma was diluted during sampling, the crystals were translucent, and the measurements were conducted 
manually, it was possible to clearly differentiate crystal dimensions even for overlapped particles. However, the use of manual image analysis impacted the number of samples and thereby crystals that could be visually examined and measured. A practical number of measurements was chosen based on the difference between relative variations in the mean crystal dimensions over sample number and the crystal size variations between steady states. Following this approach, a sample number of 700 crystals per steady state was found to be optimal to determine variations in crystal size within reasonable analysis times. The relative variations in the mean size with the sampling number are provided in supporting information, and consequences of the measurement uncertainty will be discussed throughout this paper. For a thorough measurement, all the complete crystals in a given picture must be analyzed before the next picture is studied. This was done by dividing the image into 12 segments of equal size and analyzing all the crystals in each region. This approach minimizes the operator error during sample analysis, as it becomes more difficult to overlook the smaller crystals.

\section{EXPERIMENTAL RESULTS}

Solubility curve. The obtained solubility curve for Melitracen $\mathrm{HCl}$ in ethanol is reported in Figure 4. The solubility of the system has an exponential temperature dependency for temperatures between 5 and $35^{\circ} \mathrm{C}$. The fitted exponential expression will be used to determine supersaturations in both the experimental data and the mathematical model. 


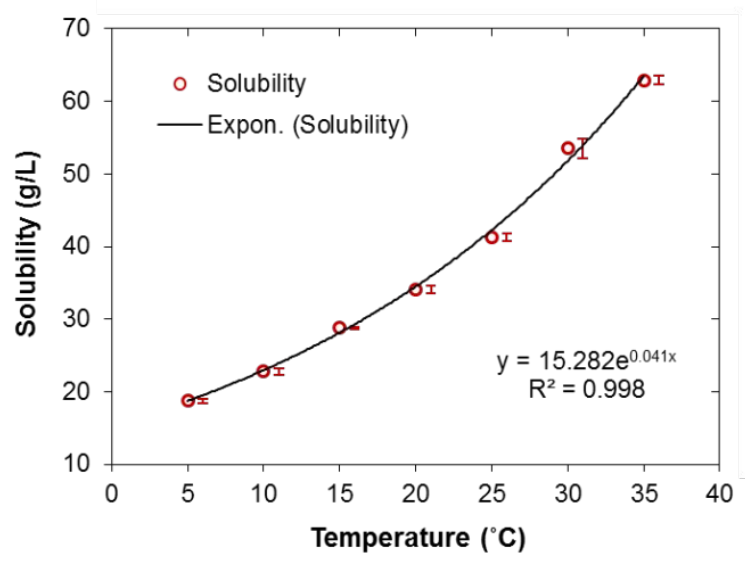

Figure 4. Solubility curve for Melitracen hydrochloride in ethanol. The error bars show the standard deviation between the triplicate HPLC samples. These are placed at the side of each point for clarity.

Evolution to steady state and reproducibility. As a first step to assess the reliability of the MSMPR data, three continuous crystallization experiments were conducted in single stage aiming for identical process conditions. A summary of the steady state conditions for each repetition is provided in Table 1.

Table 1. Steady state conditions for the three repetitions in single stage MSMPR crystallization. The concentration values include the mean \pm standard deviation of the four replicates at steady state.

$\begin{array}{ccccccc}\text { Experiment } & \mathrm{C}_{0}(\mathrm{~g} / \mathrm{L}) & \mathrm{T}\left({ }^{\circ} \mathrm{C}\right) & \tau(\mathrm{min}) & \mathrm{C}_{\mathrm{ml}}(\mathrm{g} / \mathrm{L}) & \sigma^{a} & {\text { Yield }(\%)^{b}}^{b} \\ \mathrm{R} 1 & 122.0 \pm 3.4 & 10 & 60 & 33.7 \pm 2.0 & 0.46 & 72.4 \\ \mathrm{R} 2 & 127.2 \pm 3.0 & 10 & 60 & 34.2 \pm 0.6 & 0.49 & 73.1 \\ \mathrm{R} 3 & 128.4 \pm 0.6 & 10 & 60 & 33.6 \pm 0.1 & 0.46 & 73.8\end{array}$

${ }^{a}$ The supersaturation $\sigma$ is calculated as $\left(\mathrm{C}_{\mathrm{ml}}-\mathrm{C}_{\mathrm{sat}}(\mathrm{T})\right) / \mathrm{C}_{\mathrm{sat}}(\mathrm{T})$, for which a value of 0 corresponds to the thermodynamic equilibrium. ${ }^{b}$ The step yield is calculated as $100\left(\mathrm{C}_{0}-\mathrm{C}_{\mathrm{ml}}\right) / \mathrm{C}_{0}$. 
Following a similar approach to the one described by Hou et al., ${ }^{10}$ the system reproducibility was assessed for different starting suspensions. R1 started from an equilibrium suspension using crystals from the full-scale batch process. R2 started from the steady state suspension from R1, which was left to reach equilibrium before the experiment. At the end of $\mathrm{R} 2,30 \mathrm{~mL}$ of the feed solution were pumped into the steady state magma and the crystals were allowed to grow overnight in the agitated crystallizer $(150 \mathrm{rpm})$. The resulting suspension was used as the starting point in R3. As it will be discussed from the SEM and microscopy analysis, the full-scale batch and MSMPR crystals present significantly different crystal habits. Thus, the reproducibility has been studied for starting suspensions including different shapes and starting crystal sizes.

As it can be seen from Table 1, the three repetitions gave similar mother liquor concentrations and yields. The standard deviation of each concentration value is a function of the concentration fluctuations at steady state. These are at a similar order than the variations in the steady state mother liquor concentration for different repetitions. Furthermore, the feed concentrations tend to give a higher deviation than the crystallizer mother liquor, presumably because of the higher dilution factor that these samples require for HPLC analysis.

The steady state consistency is further verified with the FBRM data from the three repetitions and reported in Figure 5. As it has been seen for other systems, the experiment starts with a washout phase lasting for 1-2 residence times, when the initial suspension is removed at a faster rate than new crystals are generated. ${ }^{11}$ This is seen as a drop in the total number of counts and, for this system, as an increase of the mean chord length due to the growth of the seed crystals. The washout phase leads to an increase in supersaturation that eventually triggers a system response in the form of nucleation. This results in an increase of the total number of FBRM counts and a decrease in the mean chord length. The system reaches a pseudo steady state after 4 
residence times. However, the chord length distribution does not stabilize until residence time 89. This behavior was consistent throughout all the experiments in this work. To ensure consistent concentration and size distribution data, HPLC and microscope sampling were conducted after residence time 9.

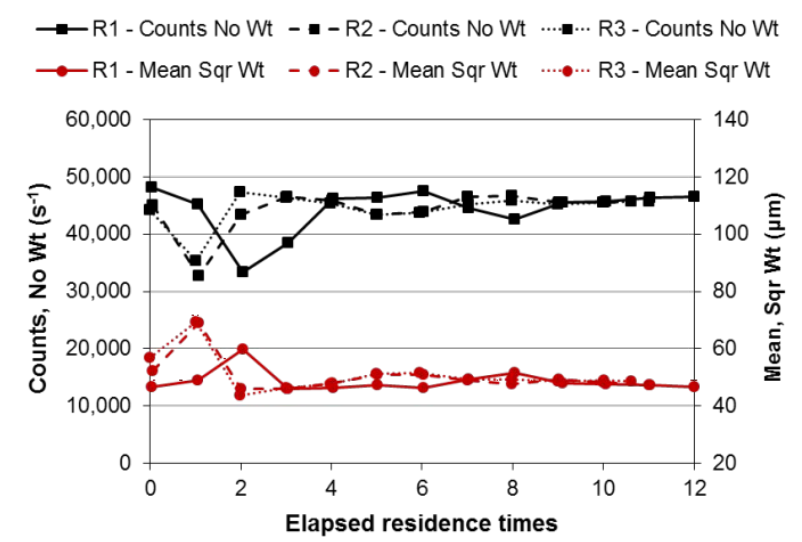

Figure 5. Evolution of the FBRM counts and square weighted mean chord length throughout the three repetitions.

Continuous crystallization experiments. A set of continuous crystallization experiments were conducted to serve as a basis for the characterization of the MSMPR cascade. For the experimental design, a constant temperature of $10{ }^{\circ} \mathrm{C}$ was selected at the final crystallization step. The objective in the implemented process will be to obtain a final mother liquor concentration that is close to the API solubility at room temperature. This approach limits unwanted crystallization during suspension transfer and filtration. The experimental conditions and steady state concentrations are summarized in Table 2.

Table 2. Steady state results for the continuous crystallization experiments. Those experiments containing two columns were conducted in two stage crystallization, showing data for stage 1 (S1) and stage $2(\mathrm{~S} 2)$. The concentration values include the mean \pm standard deviation of the four replicates at steady state. 


$\begin{array}{cccccccc}\text { Exp. } & \mathrm{C}_{0}(\mathrm{~g} / \mathrm{L}) & \begin{array}{c}\text { MSMPR } \\ \text { stage }\end{array} & \mathrm{T}\left({ }^{\circ} \mathrm{C}\right) & \tau(\mathrm{min}) & \mathrm{C}_{\mathrm{ml}}(\mathrm{g} / \mathrm{L}) & \sigma^{a} & \text { Yield }(\%)^{b} \\ \text { E1 } & 130.2 \pm 1.2 & \mathrm{~S} 1 & 10 & 60 & 34.3 \pm 0.1 & 0.49 & 73.6 \\ \text { E2 } & 127.9 \pm 0.9 & \mathrm{~S} 1 & 10 & 90 & 33.0 \pm 0.3 & 0.43 & 74.2 \\ \text { E3 } & 125.8 \pm 1.3 & \mathrm{~S} 1 & 10 & 120 & 30.3 \pm 0.2 & 0.32 & 75.9 \\ \text { E4 } & 90.4 \pm 0.9 & \mathrm{~S} 1 & 10 & 60 & 32.1 \pm 0.4 & 0.40 & 64.4 \\ \text { E5 } & 60.2 \pm 1.5 & \mathrm{~S} 1 & 10 & 60 & 31.8 \pm 0.1 & 0.38 & 47.1 \\ \text { E6 } & 127.5 \pm 0.4 & \mathrm{~S} 1 & 20 & 30 & 44.8 \pm 0.7 & 0.29 & 64.9 \\ & & \mathrm{~S} 2 & 10 & 30 & 28.6 \pm 0.3 & 0.24 & 77.6 \\ \text { E7 } & 127.0 \pm 1.0 & \mathrm{~S} 1 & 20 & 60 & 43.3 \pm 0.3 & 0.25 & 65.9 \\ & & \mathrm{~S} 2 & 10 & 60 & 27.7 \pm 0.6 & 0.20 & 78.1 \\ \mathrm{E} 8 & 127.7 \pm 2.2 & \mathrm{~S} 1 & 30 & 30 & 66.6 \pm 0.9 & 0.27 & 47.8 \\ & & \mathrm{~S} 2 & 10 & 30 & 32.7 \pm 0.7 & 0.42 & 74.4 \\ \mathrm{E} 9 & 125.9 \pm 1.2 & \mathrm{~S} 1 & 30 & 60 & 62.6 \pm 1.0 & 0.20 & 50.3 \\ & & \mathrm{~S} 2 & 10 & 60 & 30.2 \pm 0.7 & 0.31 & 76.0\end{array}$

${ }^{a}$ The supersaturation $\sigma$ is calculated as $\left(\mathrm{C}_{\mathrm{ml}}-\mathrm{C}_{\mathrm{sat}}(\mathrm{T})\right) / \mathrm{C}_{\mathrm{sat}}(\mathrm{T})$, for which a value of 0 corresponds to the thermodynamic equilibrium. ${ }^{b}$ The step yield is calculated as $100\left(\mathrm{C}_{0}-\mathrm{C}_{\mathrm{ml}}\right) / \mathrm{C}_{0}$.

The effects of feed concentration and residence time on crystallization kinetics were investigated first in single stage (E1-5). Then, the experiments were extended to investigate the effects of performing part of the separation at a higher temperature (E6-9, stage 1). The multistage crystallization experiments (E6 to E9) were designed to have the same total residence time as experiments E1 and E3. This allows for a direct comparison of the effect of number of stages and first stage temperature on crystallization yield. As it was recently reported by Li et al., ${ }^{7}$ increasing the number of stages is a practical method to attain higher yields for a constant residence time and final stage temperature. Working with multiple stages allows part of the crystallization process to be conducted at a higher temperature, which typically results in faster 
crystallization rates. The temperature of the first stage plays an important role in the extent of this promotion. ${ }^{6}$

Note that, for the same feed concentration and total residence time, the highest product recoveries were obtained when the first stage operates at $20^{\circ} \mathrm{C}(\mathrm{E} 6$ and $\mathrm{E} 7)$, while a first stage temperature of $30{ }^{\circ} \mathrm{C}$ (E8 and E9) does not offer a significant advantage against single stage crystallization (E1 and E3) from a yield perspective. This behavior shows that higher temperatures in the first stage do not necessarily lead to a higher productivity. Although kinetics are expected to be faster at $30{ }^{\circ} \mathrm{C}$, increasing the crystallization temperature reduces the attainable step yield in the first stage. This means that most of the solute recovery is left for the second stage that is subject to slower kinetics. Furthermore, the faster kinetics in the first stage lead to lower steady state supersaturations. For the same residence time, the crystallizers operating at $30{ }^{\circ} \mathrm{C}$ have the lowest supersaturation observed in the first crystallization stage. From a yield perspective, operating this close to equilibrium is not efficient in an intermediate stage as it lowers the overall productivity of the crystallization process.

Crystal habit of the full-scale batch and MSMPR crystals. Figure 6 shows SEM pictures of the crystals obtained from lab-scale MSMPR crystallization (E8) and the formulation crystals from the full-scale batch process in Lundbeck. Both samples shared the same crystal structure as verified by the XRPD patterns supplied in supporting information. 

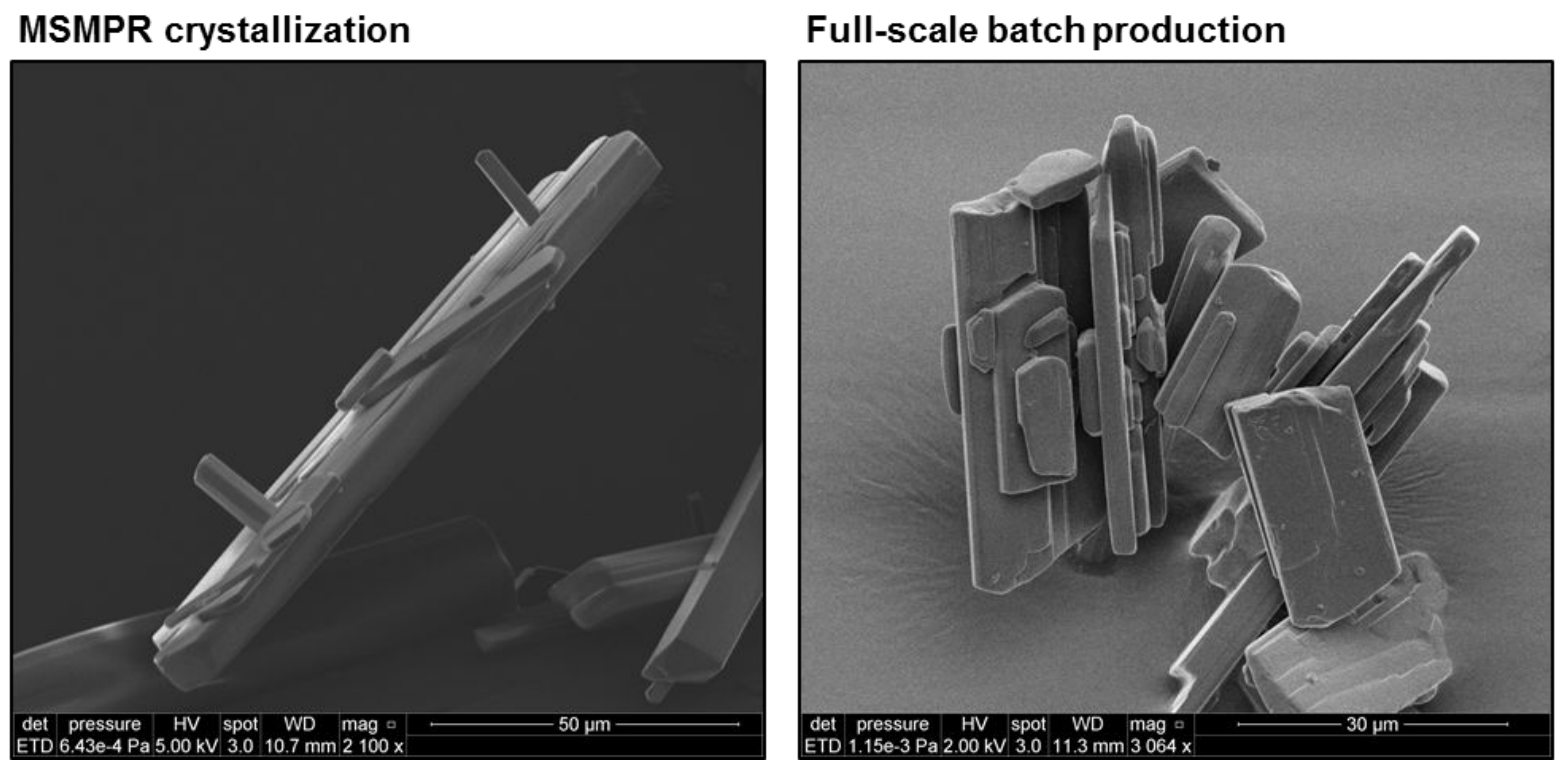

Figure 6. SEM pictures displaying the 3D shape of the API samples collected from the MSMPR process, compared to those supplied from full-scale batch production. Note that the two pictures have a different scale bar.

Crystal habit is a main function of the internal structure of the crystals and the crystallization conditions. These conditions include the choice of solvent, the presence of impurities and the rate of crystal growth. ${ }^{44}$ Furthermore, mechanical stress can have a significant impact on crystal shape through attrition and fracture.

Although both processes produce crystals with a plate morphology and a similar relation between the crystal height and width, the full-scale batch product exhibits a significantly shorter crystal length. In contrast with the product from MSMPR crystallization, the batch product was subject to substantial mechanical stress in downstream processing. The different crystal habit could be explained as a consequence of crystal breakage in full-scale production. However, this hypothesis cannot be verified without a proper study of the effect of crystallization kinetics on crystal habit. Even though both processes use the same solvent and start from a purified solution, the nature of the batch process and the supersaturation profile are completely different. The 
source of the different morphology will later be investigated from the effect of process conditions on crystal habit and from the behavior of the system upon crystal breakage.

Effect of process conditions on crystal habit. Crystals present multiple crystallographic planes. In this work, we have simplified the crystal morphology to three characteristic dimensions: width, length and height, the latter being the shortest dimension that is hidden in the 2D projection. For the shape analysis, it is assumed that the crystals fall flat in the sample, displaying their two largest dimensions. This is promoted by using a sample presentation method that dilutes the crystallization magma and by the significant difference in surface area between planes in elongated crystals.

Figure 7 shows the steady state crystal shape distribution of the first stage MSMPR magma during four runs at variable supersaturations and temperatures.

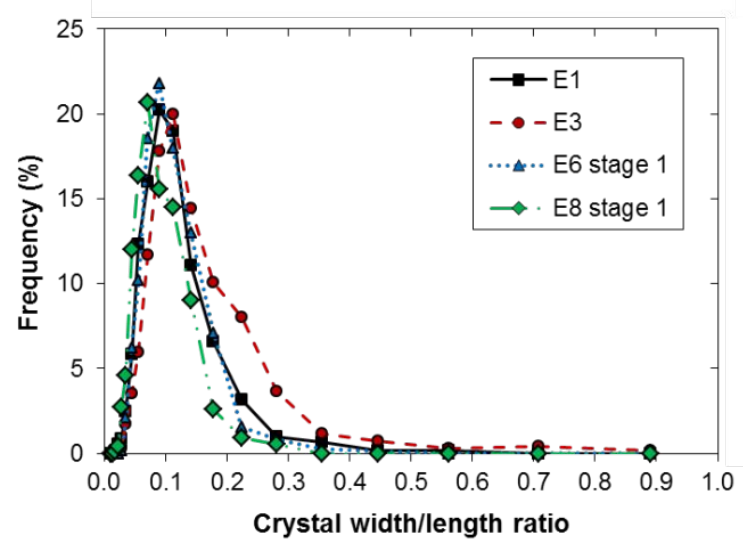

Figure 7. Crystal shape distribution, expressed as the ratio between crystal width and crystal length, for the $2 \mathrm{D}$ projection of the steady state magma in different runs. The experimental conditions cover the range of supersaturations from 0.27 to 0.49 and temperatures from $10{ }^{\circ} \mathrm{C}$ to $30{ }^{\circ} \mathrm{C}$.

The objective behind the analysis is to detect variations in crystal shape caused by the different conditions of crystal growth. As it was verified during the later analysis of the population 
balance, experiment E3 and E8 had, respectively, the smallest and largest crystal growth rate in the first MSMPR stage. Populations in the second crystallization stage were left out of this analysis, as they are susceptible to crystal breakage during suspension transfer. Results in Figure 7 demonstrate that, in this range of operating conditions, the rates of crystal growth for crystal width and crystal length are proportional regardless of the process temperature and supersaturation.

Note that the crystal shape distribution for run E3 appears wider than the rest. Different mechanisms, including breakage, size-dependent growth and growth rate dispersion in one dimension, could cause a broadening of the crystal shape distribution. These mechanisms can be investigated from the size dependence of the crystal shape and from the population balance in the MSMPR crystallizer. The first can be investigated using a shape vs length diagram as shown in Figure 8 .
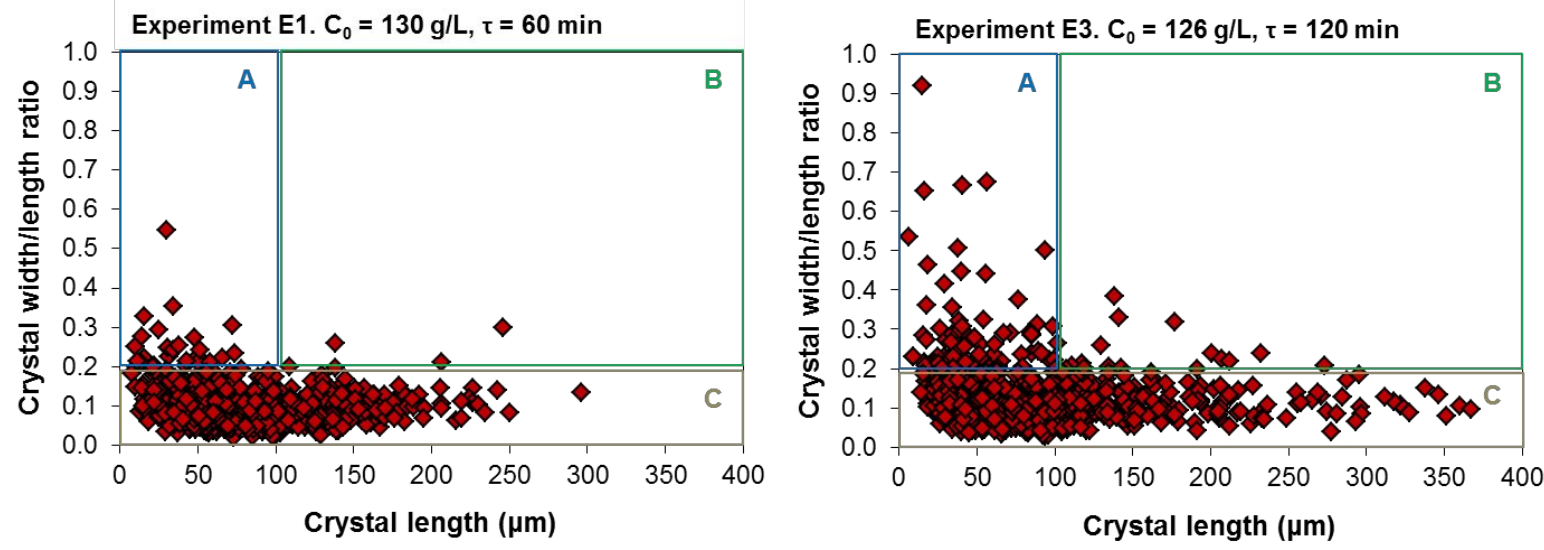

Figure 8. Crystal shape diagrams for E1 and E3, containing approximately 700 crystals each. The diagrams have been divided in three regions $(\mathrm{A}, \mathrm{B}, \mathrm{C})$ to facilitate the discussion. Inspection of figures 7 and 8 reveals that over $95 \%$ of the crystals fall in region $\mathrm{C}$ (width/length $<0.2$ ) for most of the experiments. For a system with negligible breakage where the growth rates in each dimension have a linear dependency, the mean aspect ratio should 
remain constant regardless of crystal size. As it can be seen from Figure 8, the distribution broadening from Figure 7 occurs preferentially at the lower crystal lengths (region A). Runs E1 and E3 were conducted at the same feed concentration and temperature but at different residence times. It can be inferred from region $\mathrm{C}$ in Figure 8 that a longer residence time leads to an increase in the length of the crystals in the magma. However, longer crystals and extended holding times are more susceptible to crystal fracture. The increased population in region A is presumably a consequence of breakage, leading to the appearance of crystal fragments with a short length and a square-like 2D projection.

The appearance of these fragments would be accompanied by a broadening of the crystal shape distribution, as those crystals that break near the edges will still retain a crystal shape within a reasonable value. However, this broadening is very small in this system due to the limited extent of crystal breakage. From the samples obtained in the first stage, the magma in E3 presents the worst case scenario for this phenomenon.

Crystal breakage in multistage crystallization. To investigate the impact of suspension transfer and second stage crystallization on crystal breakage, samples of the crystallization magma were collected at three different locations in the cascade: at the first MSMPR stage, at the outlet of the pump transferring the magma between crystallizers (P3), and at the second MSMPR stage. Experiment E7 was selected for this purpose, as it gave the highest suspension density in the first stage crystallizer. In Figure 9, a sample of the optical microscopy images of the three points are displayed, accompanied by the shape diagrams of each sample. To facilitate the discussion, the same has been done for the full-scale batch product that is used as a starting suspension in the MSMPR crystallizer. 

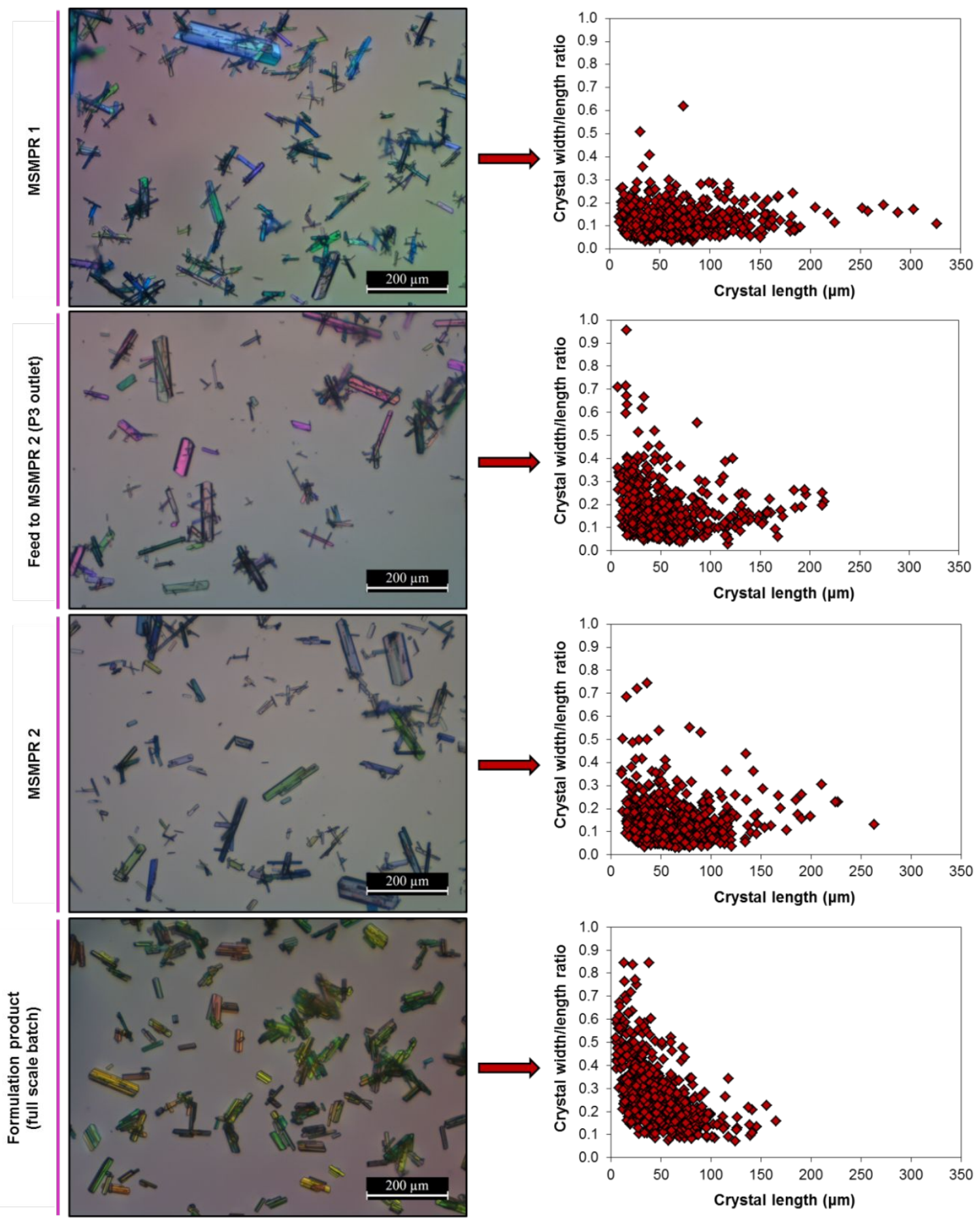

Figure 9. Tracking crystal breakage with optical microscopy. An example of a magma picture is placed side by side with the $2 \mathrm{D}$ shape diagrams for 700 crystals (multiple pictures) at three sampling points in the MSMPR cascade and for the commercial batch product. This figure, read from top to bottom, follows the hypothesis described in Figure 1. 
Note that the largest difference in crystal shape occurs at the pump transferring the suspension from MSMPR 1 to MSMPR 2. Suspension transfer takes less than 5 seconds, and thus it may be assumed that the extent of crystallization is negligible during product removal. The observed variations are solely related to crystal breakage during pumping.

Interestingly, the crystal shape distribution is retained in the second crystallizer. The experiment yielded a solute recovery of $78.1 \%$, with the first $65.9 \%$ being recovered in the first crystallizer. Similar to other systems, the second MSMPR unit has a small impact on the crystal size distribution. ${ }^{7,11}$ This is because most of the solute mass is recovered in the first stage. The second stage receives a suspension as feed, and the large amount of crystals provide an extended area for solute deposition. Furthermore, the second stage operates at lower temperatures and reduced supersaturations, which limit the overall kinetics of crystallization.

The shape diagram for the formulation product presented in Figure 9 exhibits a broad shape distribution with a size-dependent crystal habit. As suspected from the SEM images in Figure 6 and supported by the observed breakage in P3, the API crystals are highly sensitive to crystal breakage in their largest dimension. Considering the similarity between the crystallization magma at the outlet of $\mathrm{P} 3$ and that of the formulation product, it is expected that crystal breakage during the downstream steps in a full-scale continuous process will yield crystals with a similar shape than those currently obtained in batch production. Thus, there is no point in designing a gentle treatment from an industrial perspective.

As introduced earlier in the "motivation and hypothesis" section, for plate or needle crystals, crystal breakage across the smallest plane rarely has an impact on crystal width or height. The smaller volume of the broken crystal is compensated by the birth of a new crystal, a 'fragment' 
of the original, that retains the same size for those two dimensions. The total crystal mass sharing that crystal width or height remains the same. The volumetric crystal size distributions of run E7 based on crystal width and crystal length have been reported in Figure 10, together with the quantitative shape distributions corresponding to the diagrams in Figure 9. The observed 35\% reduction in the mean crystal length is significantly higher than the previously studied measurement reproducibility, and it is further supported by the significant shape variations observed in Figure 9. These results demonstrate that crystal breakage has a significant effect on the crystal length distribution, while the impact on crystal width falls below the reproducibility of the image analysis method.
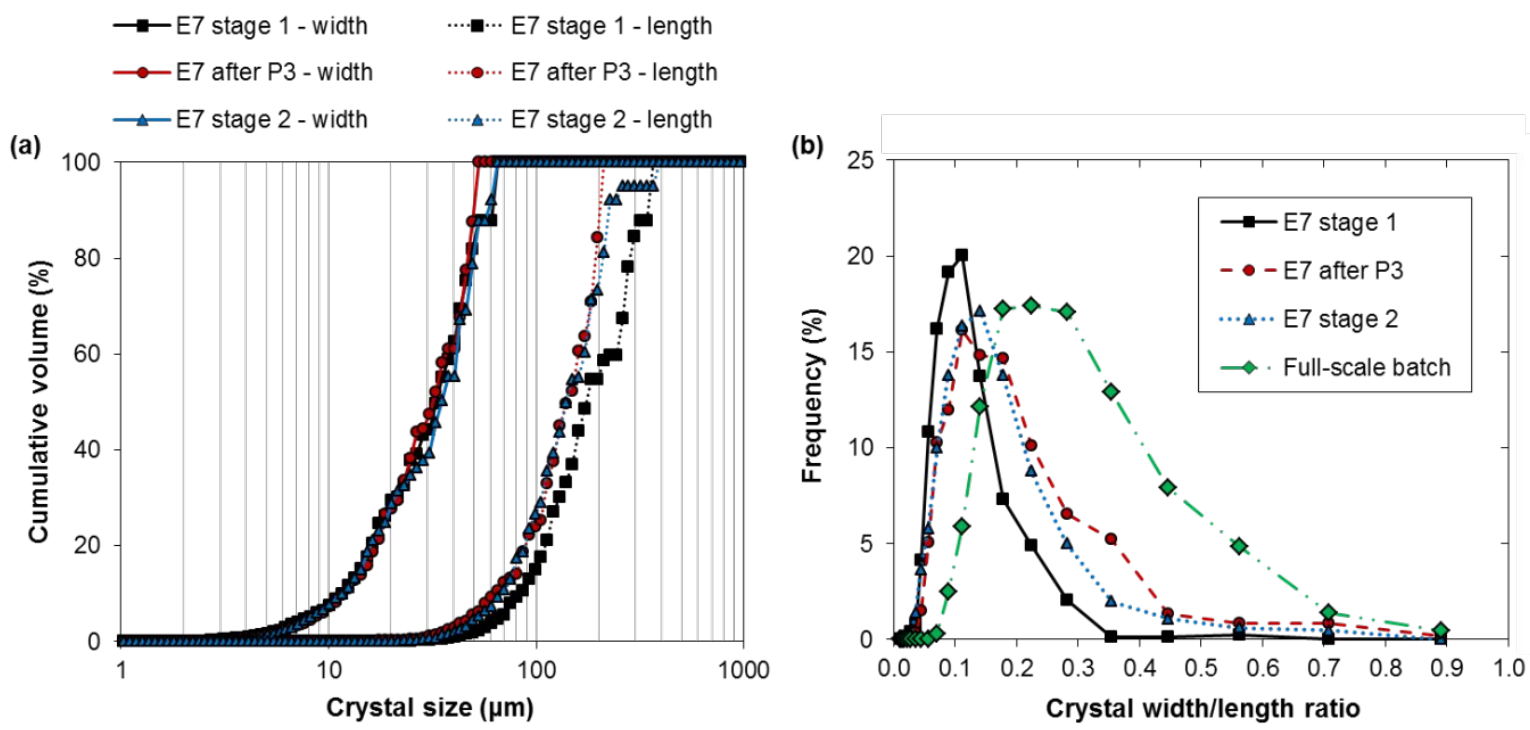

Figure 10. 2D crystal size (a) and shape (b) distributions at different locations of the steady state system in experiment E7.

The consistency of the crystal width distribution with crystal breakage provides a significant advantage for the early assessment of API quality. Contrary to most crystal size distributions based on an equivalent dimension, the crystal width distribution is expected to remain consistent through downstream production, as it is based on a crystal dimension that is not sensitive to 
breakage. Thus, focusing the optimization steps on controlling this distribution simplifies the development of the crystallization process and the later modelling of the downstream unit operations.

\section{OPTIMIZATION FOR A RELEVANT CRYSTAL DIMENSION}

Selection of a mathematical model. Using a common approach for MSMPR crystallizers, the crystallization rate equations have been determined by fitting a mathematical model that simultaneously solves the population balance and the mass balance for each crystallizer.

Determination of multiple crystal dimensions enables the application of multidimensional population models to predict crystal size and shape. As demonstrated by quantitative image analysis, the crystal shape is independent of the crystal growth rate in the MSMPR crystallizer, and only crystal breakage induces significant changes in the 2D projection of the magma. Given that most of the crystal breakage occurs in the pumps and that this phenomenon is hardly avoidable during downstream processing and formulation, a unidimensional population model based on crystal width is sufficient for this system. The model will be using a shape factor that assumes negligible crystal breakage, as well as populations that are independent of this phenomenon. Thus, this approach allows for the independent evaluation of size-dependent growth from the logarithmic population density plot.

The use of population models based on a non-fragile dimension has limitations. If the extent of crystal breakage was significantly higher, the increased amount of dislocations in the broken crystal plane would lead to a faster growth rate in the perpendicular dimension. In addition, even though the increase in surface area upon plate breakage is relatively small, extensive fracture will cause a significant increase in the available surface area for crystal growth. Consequently, the 
second MSMPR would exhibit lower supersaturations and affect the rates of crystal growth in the other crystal dimensions. Finally, the crystals do not necessarily have to break on the same dimension, or following a straight plane. High degrees of crystal breakage could affect more than one dimension or produce an excessive amount of fines. This approach has been valid for the system studied here, but further consideration would be required for each case.

Population and mass balances for the MSMPR cascade. The unidimensional population balance of a steady state MSMPR crystallizer with negligible agglomeration and breakage was described by Randolph and Larson as in eq $1 .{ }^{45}$

$$
\frac{d\left(G n_{i}\right)}{d L}+\frac{n_{i}-n_{i-1}}{\tau}=0
$$

When the system follows McCabe's $\Delta \mathrm{L}$ law, the crystal growth rate is not a function of crystal size. The population balance in eq. 1 can then be integrated for both crystallizers, using the boundary condition $\mathrm{n}(0)=\mathrm{n}^{0}$ and considering that the first crystallizer is not seeded:

$$
\begin{gathered}
n_{1}(\mathrm{~L})=n_{1}{ }^{0} \exp \left(\frac{-L}{G_{1} \tau_{1}}\right) \\
n_{2}(\mathrm{~L})=n_{2}^{0} \exp \left(\frac{-L}{G_{2} \tau_{2}}\right)+n_{1}{ }^{0}\left[\frac{G_{1} \tau_{1}}{G_{1} \tau_{1}-G_{2} \tau_{2}}\right]\left[\exp \left(\frac{-L}{G_{1} \tau_{1}}\right)-\exp \left(\frac{-L}{G_{2} \tau_{2}}\right)\right]
\end{gathered}
$$

Equations 2 and 3 define the population balance in the first and second stage, respectively. $\mathrm{n}^{0}$ is the population of zero-sized nuclei and it can be calculated from the rates of nucleation and crystal growth:

$$
n_{i}^{0}=\frac{B_{i}}{G_{i}}
$$

The suspension density for each crystallizer can be obtained from the third moment of the population balance, the density of the solid phase $\rho$ and a volumetric shape factor $\mathrm{k}_{\mathrm{v}}$, assuming that the crystal shape is independent of the crystallization conditions.

$$
M_{T}=k_{v} \rho \int_{0}^{\infty} L^{3} n d L
$$


The mass balance for the API in each crystallizer can be written as

$$
C_{0}=C_{m l}+M_{T}
$$

Finally, the rates of nucleation and crystal growth can be expressed from semi-empirical equations, where the mass balance in equation 6 can be incorporated to express supersaturation as a function of suspension density and feed concentration:

$$
\begin{gathered}
B=k_{b 0} \exp \left(\frac{-E_{b}}{R T}\right) M_{T}{ }^{j}\left(\frac{C_{0}-M_{T}-C_{\text {sat }}(T)}{C_{\text {sat }}(T)}\right)^{b} \\
G=k_{g 0} \exp \left(\frac{-E_{g}}{R T}\right)\left(\frac{C_{0}-M_{T}-C_{\text {sat }}(T)}{C_{\text {sat }}(T)}\right)^{g}
\end{gathered}
$$

Equations 2, 5, 7 and 8 will have a single solution that satisfies both the mass balance and the population balance in the first crystallizer. For a given feed concentration, crystallization temperature and residence time, this system of equations can be solved using the MATLAB function lsqnonlin to find the values of $\mathrm{B}, \mathrm{G}, \mathrm{M}_{\mathrm{T}}$ and $\mathrm{n}$ in the first MSMPR stage. Then, the system of equations $3,5,7$ and 8 can be solved to obtain the relevant data for the second crystallization stage.

Determination of the kinetic rate equations. Prediction of the steady state population requires knowledge on the crystallization rate equations, the density of the solid phase and the shape factor of the crystals. The rates of nucleation and crystal growth as described in equations 7 and 8 are based on seven parameters that can be obtained by fitting the prediction model to the experimental population distributions.

The volumetric shape factor based on crystal width was established from image analysis of the crystallization magma. A mean aspect ratio between crystal length and width of 0.89 was determined from the mode of the crystal shape distributions of the experiments in single stage crystallization. Based on SEM observations, the crystal height was assumed to be proportional to 
the crystal width for all the studied conditions. Assuming that the height is a third of the crystal width, the $\mathrm{k}_{\mathrm{v}}$ value was calculated from the ratio between crystal dimensions:

$$
\begin{gathered}
l=\frac{w}{0.089} \quad h=\frac{w}{3} \\
V_{c}=k_{v} L^{3}=\operatorname{lh} w \underset{\overline{L=w}}{\Longrightarrow} k_{v}=\frac{1}{0.089 \cdot 3}=3.74
\end{gathered}
$$

The density of the crystalline API was set at $1280 \mathrm{~kg} / \mathrm{m}^{3}$. For a given shape factor and solid density, the experimental population distribution can be obtained using equation 11 .

$$
n_{\text {exp }}(w)=\frac{v o l(w) M_{T, \exp }}{\rho k_{v} w^{3} \Delta w}
$$

The obtained population distributions follow the trend displayed in Figure 11. The linear nature of the logarithmic population density plot demonstrates that the system follows McCabe's $\Delta \mathrm{L}$ law, and thus that the selected size-independent growth model is appropriate for this system. Note that crystal widths smaller than $2.5 \mu \mathrm{m}$ deviate from the linear trend presenting lower populations. This behavior is presumably related to the limitations of image analysis. Crystals of this size are too thin to be detected and analyzed at the used microscope magnification, and thus a smaller amount is detected during image analysis. Since the volumetric mean widths in this work are at the order of 20 to $40 \mu \mathrm{m}$, and crystals below $2.5 \mu \mathrm{m}$ never accounted for more than $0.3 \%$ of the suspension mass, this limitation should not have a significant impact on the accuracy of the model. 


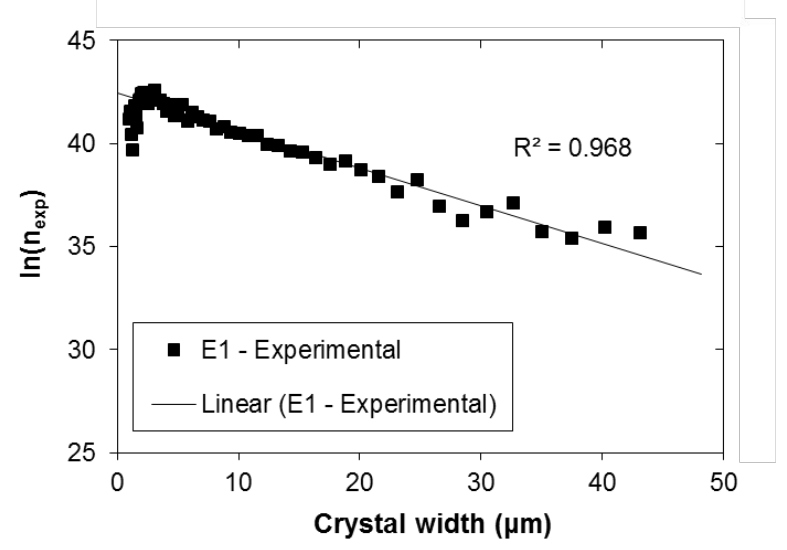

Figure 11. Logarithmic population density plot for run E1, including a linear fit for the size range from 3 to $40 \mu \mathrm{m}$.

The fluctuations observed for the larger sizes in the population density plot are a consequence of the analysis method. In this work, 700 crystals were sufficient to detect variations in the crystal size distribution and to obtain a mean size with reasonable accuracy. However, this sample number does not allow to obtain a smooth distribution at the larger crystal sizes, where a single channel can include less than 5 crystals. Those crystals, despite being a small amount, constitute a large fraction of the suspension mass because of their size.

Based on the number of crystals that are present in the larger bins, a smooth distribution would require a sample number 1-2 orders of magnitude higher. This is not practical for manual image analysis, but could easily be achieved with an appropriate algorithm. Fluctuations in the volumetric size distribution, as observed in Figure 10, produce a scatter in the population density plot and increase the uncertainty of the determined experimental kinetics. To limit the impact of this scatter, the effective rates of nucleation and crystal growth were fitted for populations between 3 and $40 \mu \mathrm{m}$. 
The kinetic parameters based on crystal width were obtained using the MATLAB function lsqnonlin. Based on an initial guess for the parameter vector $\theta=[\mathrm{kbo}, \mathrm{Eb}, \mathrm{j}, \mathrm{b}, \mathrm{kg} 0, \mathrm{Eg}, \mathrm{g}]$, the best fit of kinetic parameters is obtained by solving the least squares minimization problem:

$$
\min _{\theta} F=\sum_{E 1-9} \sum_{w=3 \mu m}^{40 \mu m}\left[\ln \left(n_{\exp }(w)\right)-\ln (n(w))\right]^{2}
$$

To account for the typically small supersaturations in the second crystallization stage, the population data from the 13 crystallizers in E1-9 (including both stages) were used for parameter estimation. The obtained kinetic parameters for the best fit to equation 12 are summarized in Table 3 .

Table 3. Fitted kinetic parameters for MSMPR crystallization of Melitracen $\mathrm{HCl}$ in ethanol.

$\begin{array}{ccc}\text { Parameter } & \text { Value } & \text { Units } \\ \mathrm{k}_{\mathrm{b} 0} & 4.79 \cdot 10^{22} & \mathrm{~m}^{-3} \mathrm{~s}^{-1} \\ \mathrm{E}_{\mathrm{b}} & 73.0 & \mathrm{~kJ} / \mathrm{mol} \\ \mathrm{j} & 0.56 & - \\ \mathrm{b} & 2.60 & - \\ \mathrm{k}_{\mathrm{g} 0} & 13.1 & \mathrm{~m} / \mathrm{s} \\ \mathrm{E}_{\mathrm{g}} & 52.5 & \mathrm{~kJ} / \mathrm{mol} \\ \mathrm{g} & 0.87 & -\end{array}$

The activation energies for nucleation $\left(E_{b}\right)$ and crystal growth $\left(E_{g}\right)$ are in a similar order of magnitude with those found for MSMPR crystallization of other organic compounds, $, 611,13,46$ and show the significant temperature dependency of the rates of crystallization. The relative kinetic order $\mathrm{i}=\mathrm{b} / \mathrm{g}$ has a value of 3 , indicating that for the same suspension density shorter holding times lead to a significant reduction in the crystal size. ${ }^{45}$ This is consistent with our experimental observations. Furthermore, as expressed by the values of $b$ and $j$, nucleation is highly supersaturation dependent and receives a small impact from suspension density. 
Model verification. The quality of the data fitting and accuracy of the prediction model are verified in two different ways. First, the model predicted rates of nucleation, crystal growth and suspension densities are compared to the values obtained experimentally. The observed experimental kinetics are calculated from the best fit to equations 2 and 3, incorporating the mass balance into the calculation by means of equation 5 . The comparison between experimental and fitted kinetics is displayed in Figure 12.
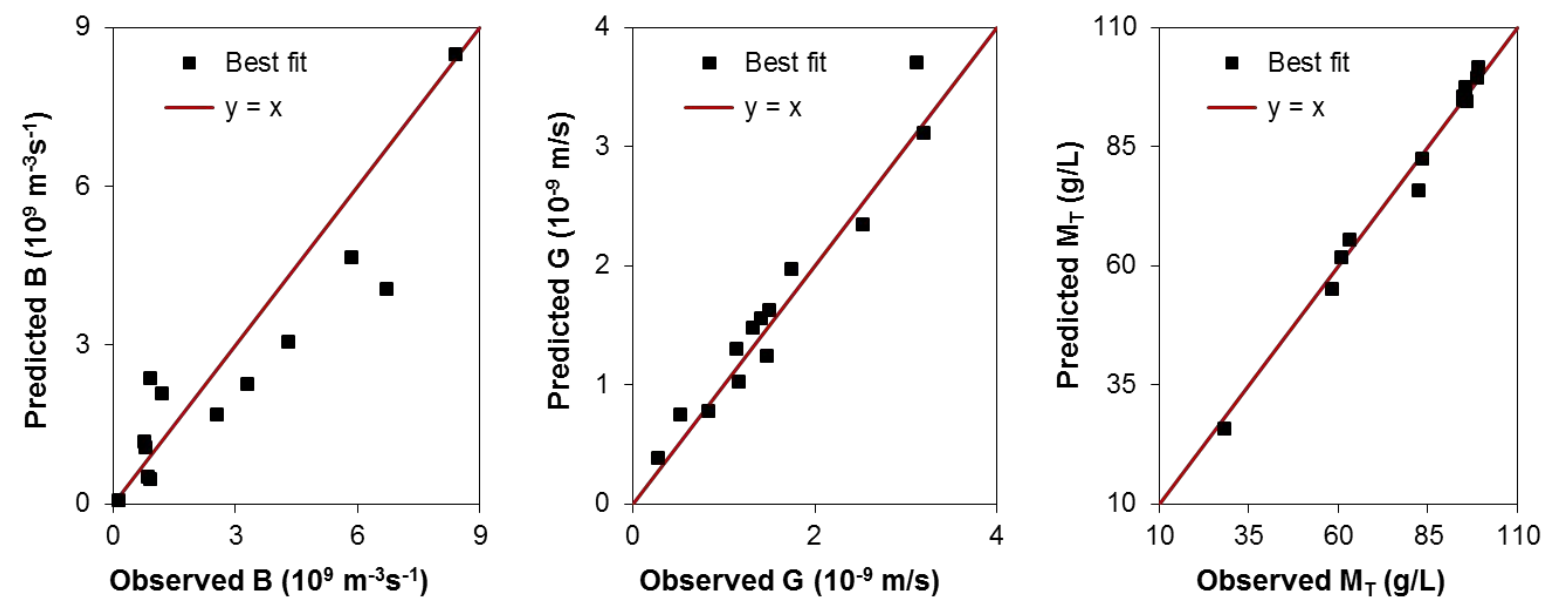

Figure 12. Correlation between the observed and predicted kinetics. The values correspond to the 13 crystallizers in 9 runs, including both single stage and multistage crystallization.

The fitted rate equations offer a very good prediction for the suspension density and growth rate in the crystallizers. However, the steady state nucleation rates are poorly predicted by these parameters. The observed deviations are a consequence of multiple factors. It is important to clarify that the plots in Figure 12 display the combined experimental and fitting errors. Since the experimental populations are determined from the volumetric size distribution, the scatter caused by a small sampling size will inevitably change the observed system kinetics. This problem is aggravated in multistage crystallization, where kinetics in the second stage depend on the fitted values for stage 1 . In addition, since the experimental kinetics are forced to comply with the 
mass balance, deviations in the slope of the logarithmic distribution will cause uncertainties in the growth rate that will propagate to the calculated nucleation rate.

To quantify the extent that these uncertainties will have on the quality of prediction, an experimental verification was considered the most appropriate. Given that the objective of the model is to predict yields and crystal size distributions, the experimental verification approach will provide an indication of the impact of the estimation errors on crystallization outcomes without including the error propagation in the calculation of experimental kinetics. For the verification experiment, crystallization temperature and residence time were varied simultaneously in two crystallization stages, using different conditions than those used in the experiments for data fitting. The observed experimental conditions and predicted suspension densities are summarized in Table 4.

Table 4. Steady state conditions of the verification experiments and prediction error.

\begin{tabular}{ccccccc}
$\mathrm{C}_{0}(\mathrm{~g} / \mathrm{L})$ & $\begin{array}{c}\text { MSMPR } \\
\text { stage }\end{array}$ & $\mathrm{T}\left({ }^{\circ} \mathrm{C}\right)$ & $\tau(\mathrm{min})$ & Yield $_{\mathrm{obs}}(\%)^{a}$ & Yield $_{\text {pred }}(\%)^{a}$ & Error $(\%)$ \\
\hline $129.5 \pm 0.2$ & $\mathrm{~S} 1$ & 25 & 40 & $56.7 \pm 0.4$ & 57.6 & 1.6 \\
& $\mathrm{~S} 2$ & 10 & 40 & $76.0 \pm 0.6$ & 78.1 & 2.7
\end{tabular}

${ }^{a}$ The step yield is calculated as $100\left(\mathrm{C}_{0}-\mathrm{C}_{\mathrm{ml}}\right) / \mathrm{C}_{0}$.

At the verification conditions, the model overestimates the steady state yield in both crystallizers. Considering that the error in the first unit propagates to the second stage, the estimation error is approximately $1.5 \%$ on each crystallizer. Slightly lower estimation errors were obtained by Power et al. in two stage MSMPR crystallization of benzoic acid. ${ }^{11}$ Regarding crystal size distribution, the model offers a good prediction for this experiment as demonstrated in Figure 13. The adequate prediction, also for the second crystallization stage, further supports that crystal breakage during suspension transfer does not have a significant impact on the predicted size distribution. 

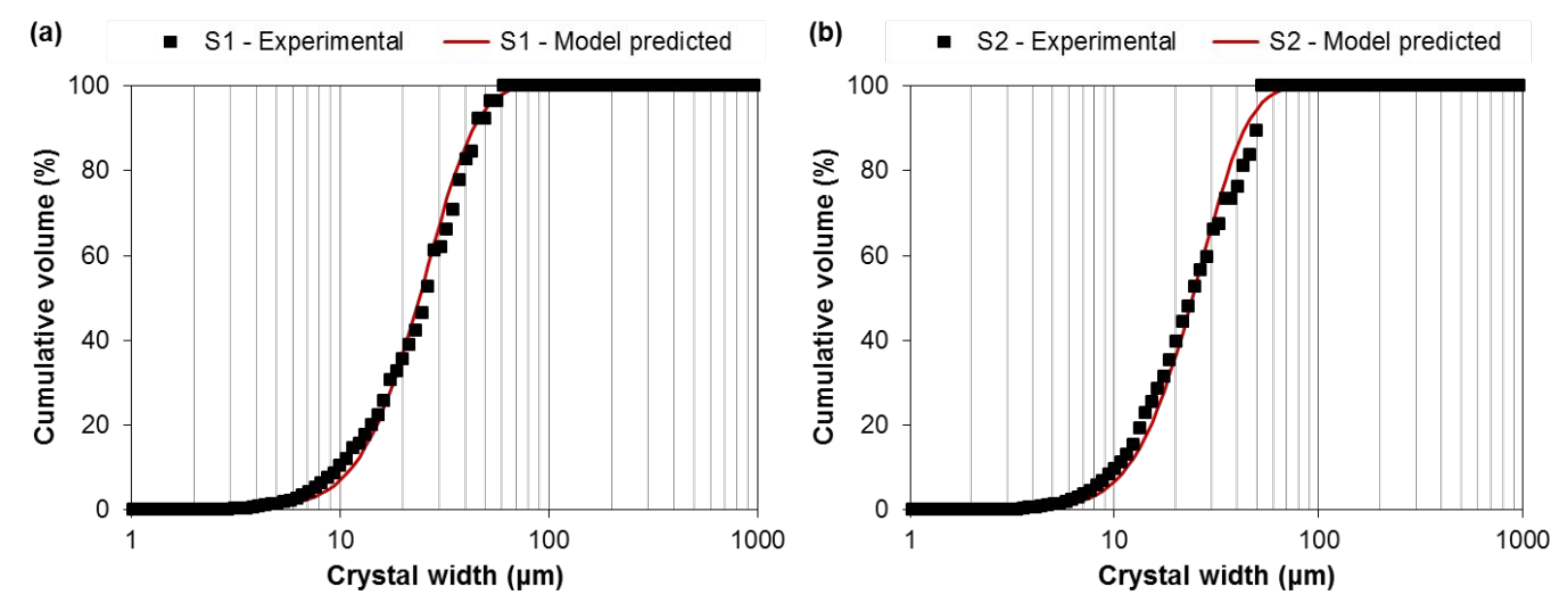

Figure 13. Comparison between the observed and predicted crystal width distributions for the verification experiment. (a) MSMPR stage 1. (b) MSMPR stage 2.

Attainable regions of crystal width. The fitted kinetic rate equations were used together with the prediction model to assess the limitations for crystal width distribution control in the investigated setup. The attainable crystal widths were assessed from the mass based mean crystal width, calculated from the third and fourth moment of the distribution: ${ }^{45}$

$$
w_{4,3}=\frac{\int_{0}^{\infty} w^{4} n d w}{\int_{0}^{\infty} w^{3} n d w}
$$

Then, an optimization problem was formulated to find the attainable regions of mass based mean crystal width for single stage and two stage MSMPR crystallization: 
Single stage:

Minimize/maximize
$C_{0}, T, \tau_{\text {tot }}$$w_{4,3}$

Subject to:

$10^{\circ} \mathrm{C} \leq \mathrm{T} \leq 30^{\circ} \mathrm{C}$

$\sigma \leq 0.6$

$M_{T} \leq 100 \mathrm{~g} / \mathrm{L}$

$C_{\text {sat }, 15{ }^{\circ} \mathrm{C}} \leq C_{m l} \leq C_{\text {sat }, 20{ }^{\circ} \mathrm{C}}$

Yield $\geq 65 \%$

\section{Two stages:}

$\underset{C_{0}, T_{1}, T_{2}, \tau_{1}, \tau_{2}}{\operatorname{Minimize}} w_{4,3}$

Subject to:

$10{ }^{\circ} \mathrm{C} \leq T_{i} \leq 30{ }^{\circ} \mathrm{C}$

$\sigma_{i} \leq 0.6$

$M_{T, i} \leq 100 g / L$

$C_{s a t, 15^{\circ} \mathrm{C}} \leq C_{m l, 2} \leq C_{s a t, 20{ }^{\circ} \mathrm{C}}$

Yield $\geq 65 \%$

$\tau_{t o t}=\tau_{1}+\tau_{2}$

$0.25 \tau_{2} \leq \tau_{1} \leq 4 \tau_{2}$

$T_{2} \leq T_{1}$

Most of the constraints are shared between the two configurations, as they are related to the system limitations and the expected operation of an implemented process. The constraints on temperature, supersaturation and suspension density are based on the lab-scale experience for this system. Higher supersaturations lead to fouling at the impeller and higher suspension densities promoted frequent clogging of the product removal stream. These constraints could be varied on a higher scale or for a different setup, provided that the system can successfully sustain the steady state at these conditions. To obtain a crystallization magma that is not subject to significant CSD variations in the transfer lines, the mother liquor concentration at the end of the crystallization process is set to have a saturation temperature between 15 and $20{ }^{\circ} \mathrm{C}$. Furthermore, the step yield of the crystallization process must be higher than $65 \%$ to obtain an efficient separation. For the two stage configuration, the residence times are constrained so that none of the crystallizers will be more than four times larger than the other. In addition, a 
temperature constraint is set so that the second crystallizer is never operating at a higher temperature than the first stage.

The optimization problem was solved using the MATLAB function fmincon. This function finds the set of conditions that minimize the value of $\mathrm{w}_{4,3}$ based on a given initial guess. Especially for two stage crystallization, where the function has 5 input parameters and a large number of constraints, the obtained minimum is highly sensitive to the initial guess. To verify that the function has found the absolute minimum, 10,000 Monte Carlo simulations were conducted with random values for the input parameters. In those simulations, the feed concentration was limited between 80 and $135 \mathrm{~g} / \mathrm{L}$, the temperatures between 10 and $30{ }^{\circ} \mathrm{C}$, and the total residence time between 60 and $120 \mathrm{~min}$. Those simulations that did not accomplish the process constraints were discarded. The attainable regions and the results from this verification are plotted together in Figure 14.


Figure 14. (a) Attainable regions for crystal width in the single stage and two stage MSMPR setup. (b) Comparison with the Monte Carlo simulation results.

The obtained attainable regions for the two stage system show a good agreement with the Monte Carlo simulations, indicating that the obtained attainable regions are close to the absolute 
minimum/maximum size for these constraints. As expected due to the increased degrees of freedom, two stage crystallization offers a much better control of the crystal size for this compound. The attainable regions have a similar shape to what has been seen previously, becoming narrow with shorter residence times until the minimum and maximum sizes eventually converge. ${ }^{15}$ This convergence point was not reached for the two stage system as total residence times below 60 min were not investigated. The conditions for minimum and maximum attainable widths are reported in Table 5.

Table 5. Conditions for minimum and maximum attainable crystal widths in two stage MSMPR crystallization. These limits are subject to the constraints in the optimization problem.

$\begin{array}{ccccccc}\mathrm{W}_{4,3}(\mu \mathrm{m}) & \mathrm{C}_{0}(\mathrm{~g} / \mathrm{L}) & \mathrm{T}_{1}\left({ }^{\circ} \mathrm{C}\right) & \tau_{1}(\mathrm{~min}) & \mathrm{T}_{2}\left({ }^{\circ} \mathrm{C}\right) & \tau_{2}(\mathrm{~min}) & {\text { Yield }(\%)^{a}} \\ \text { Min: } 18.4 & 99.7 & 18 & 15 & 10 & 45 & 65 \\ \text { Max: } 39.0 & 130.0 & 30 & 94 & 10 & 26 & 73\end{array}$

${ }^{a}$ The overall crystallization yield is calculated as $100\left(\mathrm{C}_{0}-\mathrm{C}_{\mathrm{ml}, 2}\right) / \mathrm{C}_{0}$.

Due to the dependence of crystallization kinetics on temperature and the preferential increase of the nucleation rate at high supersaturations, the largest crystal sizes are obtained by keeping the first stage temperature at $30{ }^{\circ} \mathrm{C}$ and using long residence times in the first stage. This approach ensures that the first stage operates at low supersaturations promoted by the faster kinetics and the longer holding times. To obtain smaller crystal sizes, the temperatures and residence times in both stages are adjusted so that the highest supersaturation $(0.6$, according to the constraints) is maintained in each crystallizer. Similar conditions were obtained for the minimum and maximum observed crystal widths using Monte Carlo simulations.

Image analysis from the formulation crystals gave a mass based mean crystal width of 19.5 $\mu \mathrm{m}$. Based on this value, single stage crystallization will hardly produce crystals of similar size unless the process constraints are significantly softened. Consequently, crystallization in two 
MSMPR stages is the most suitable. The effect of operating conditions on the broadness of the crystal size distribution was not investigated due to the narrow range of operating conditions that give an acceptable crystal size. To meet the desired crystal width, the process will likely have to operate at very high supersaturations and low yields. A proper study of the fouling limits for the full-scale unit would be required before selecting a set of process conditions. It is likely that the system will operate with a first crystallization unit exhibiting a short residence time and a temperature close to $20{ }^{\circ} \mathrm{C}$. The second unit will have a size approximately 3 times larger, with an operating temperature close to $10{ }^{\circ} \mathrm{C}$. Based on the production rates for the conditions of minimum size in lab-scale, the full-scale crystallization system would require an approximate total volume of $20 \mathrm{~L}(5+15 \mathrm{~L})$ to produce 10 tons of API in 300 days of operation.

\section{CONCLUSIONS}

Despite the recent advances in continuous crystallization, simultaneous control of crystal size and shape in MSMPR crystallizers still remains a challenge due to the different mechanisms that can influence crystal habit and the limited access to multidimensional size distributions. In this work, a step-by-step characterization of an MSMPR process was conducted with the assistance of quantitative image analysis. The effect of process conditions on crystal shape was studied from variations in the $2 \mathrm{D}$ projection of the crystallization magma. It was demonstrated that the operating range of supersaturations and temperatures does not have an impact on crystal habit. However, significant shape variations were observed upon suspension transfer in the pumps, leading to crystal shape distributions that are similar to those currently used in the formulation product. Crystal breakage during suspension transfer was highly selective of the largest crystal dimension, significantly reducing the aspect ratio. Using quantitative image analysis, it was 
demonstrated that the second largest crystal dimension was not affected by breakage, and thus other mechanisms including size dependent growth could be studied from its size distribution.

A mathematical model was developed for the prediction of crystal widths in single stage and two stage crystallization, for which the rate equations for nucleation and growth were determined. The presented method bypasses a complex breakage modelling for the downstream process, as the crystallizers are optimized based on a size distribution that is consistent for the formulation product.

\section{ASSOCIATED CONTENT}

\section{Supporting Information}

Evolution of the mean crystal width with sampling number, steady state classification measurements, XRPD patterns of four relevant experiments. This material is available free of charge via the Internet at http://pubs.acs.org.

\section{AUTHOR INFORMATION}

\section{Corresponding Author}

*E-mail: $\underline{\text { sk@,kt.dtu.dk. }}$

\section{Author Contributions}

The manuscript was written through contributions of all authors. All authors have given approval to the final version of the manuscript. 


\section{ACKNOWLEDGMENTS}

This work was financially supported by $\mathrm{H}$. Lundbeck $\mathrm{A} / \mathrm{S}$ and the Technical University of Denmark. The authors would like to thank Berit Wenzell and Lise Berring for their assistance with the SEM and XRPD analysis.

\section{NOMENCLATURE}

\section{Latin}

B Nucleation rate, $\mathrm{m}^{-3} \mathrm{~s}^{-1}$

b Nucleation rate order for supersaturation

$\mathbf{C}_{0} \quad$ Feed concentration, $\mathrm{g} / \mathrm{L}$

$\mathbf{C}_{\mathbf{m l}} \quad$ Mother liquor concentration, $\mathrm{g} / \mathrm{L}$

$\mathbf{C}_{\text {sat }} \quad$ Temperature dependent API solubility, g/L

$\mathbf{E}_{\mathbf{b}} \quad$ Activation energy for nucleation, $\mathrm{J} / \mathrm{mol}$

$\mathbf{E}_{\mathbf{g}} \quad$ Activation energy for crystal growth, $\mathrm{J} / \mathrm{mol}$

G Linear crystal growth rate for the characteristic dimension, $\mathrm{m} / \mathrm{s}$

g Growth rate order for supersaturation

h Crystal height, $\mathrm{m}$

j Nucleation rate order for suspension density 


$\mathbf{k}_{\mathbf{b 0}} \quad$ Pre-exponential nucleation rate factor, $\mathrm{m}^{-3} \mathrm{~s}^{-1}$
$\mathbf{k}_{\mathbf{g} \mathbf{0}} \quad$ Pre-exponential growth rate factor, $\mathrm{m} / \mathrm{s}$
$\mathbf{k}_{\mathbf{v}} \quad$ Volumetric crystal shape factor based on the characteristic dimension
$\mathbf{L} \quad$ Size of the characteristic crystal dimension, $\mathrm{m}$
$\mathbf{l} \quad$ Crystal length, $\mathrm{m}$

$\mathbf{M}_{\mathbf{T}} \quad$ Steady state suspension density, g/L

$\mathbf{M}_{\mathbf{T}, \mathbf{e x p}} \quad$ Experimental steady state suspension density, $\mathrm{g} / \mathrm{L}$

n Population density, $\mathrm{m}^{-3} \mathrm{~m}^{-1}$

$\mathbf{n}_{\exp } \quad$ Experimental population density, $\mathrm{m}^{-3} \mathrm{~m}^{-1}$

$\mathbf{n}^{0} \quad$ Population density of zero-sized nuclei, $\mathrm{m}^{-3} \mathrm{~m}^{-1}$

R Gas constant, $8.314 \mathrm{Jmol}^{-1} \mathrm{~K}^{-1}$

t Time, $\min$

T Crystallization temperature, $\mathrm{K}$

$\mathbf{V}_{\mathbf{c}} \quad$ Crystal volume, $\mathrm{m}^{3}$

vol Volume fraction of crystals sharing a characteristic size

w $\quad$ Crystal width, $m$ 
$\mathbf{w}_{\mathbf{4 , 3}} \quad$ Mass-based mean crystal width, $\mathrm{m}$

\section{Greek}

$\Delta \mathbf{L} \quad$ Channel size for a distribution based on the characteristic dimension $\mathrm{L}, \mathrm{m}$

$\Delta \mathbf{V} \quad$ Variation in the crystallizer volume during withdrawal, $\mathrm{m}$

$\Delta \mathbf{w} \quad$ Channel size for the crystal width distribution, $\mathrm{m}$

$\boldsymbol{\theta} \quad$ Parameter vector

p Density of the crystalline phase, $\mathrm{g} / \mathrm{L}$

- Supersaturation

T $\quad$ Residence time, s

\section{REFERENCES}

(1) Plumb, K. Continuous Processing in the Pharmaceutical Industry. Chem. Eng. Res. Des. 2005, $83,730-738$.

(2) Lee, S. L.; O’Connor, T. F.; Yang, X.; Cruz, C. N.; Chatterjee, S.; Madurawe, R. D.; Moore, C. M. V; Yu, L. X.; Woodcock, J. Modernizing Pharmaceutical Manufacturing: From Batch to Continuous Production. J. Pharm. Innov. 2015, 10, 191-199.

(3) Poechlauer, P.; Manley, J.; Broxterman, R.; Gregertsen, B.; Ridemark, M. Continuous Processing in the Manufacture of Active Pharmaceutical Ingredients and Finished Dosage 
Forms: An Industry Perspective. Org. Process Res. Dev. 2012, 16, 1586-1590.

(4) Chen, J.; Sarma, B.; Evans, J. M. B.; Myerson, A. S. Pharmaceutical Crystallization. Cryst. Growth Des. 2011, 11, 887-895.

(5) Alvarez, A. J.; Singh, A.; Myerson, A. S. Crystallization of Cyclosporine in a Multistage Continuous MSMPR Crystallizer. Cryst. Growth Des. 2011, 11, 4392-4400.

(6) Li, J.; Trout, B. L.; Myerson, A. S. Multistage Continuous Mixed-Suspension, MixedProduct Removal (MSMPR) Crystallization with Solids Recycle. Org. Process Res. Dev. 2016, 20, 510-516.

(7) Li, J.; Lai, T. C.; Trout, B. L.; Myerson, A. S. Continuous Crystallization of Cyclosporine: Effect of Operating Conditions on Yield and Purity. Cryst. Growth Des. 2017, 17, 10001007.

(8) Ferguson, S.; Ortner, F.; Quon, J.; Peeva, L.; Livingston, A.; Trout, B. L.; Myerson, A. S. Use of Continuous MSMPR Crystallization with Integrated Nanofiltration Membrane Recycle for Enhanced Yield and Purity in API Crystallization. Cryst. Growth Des. 2013, $14,617-627$.

(9) Quon, J. L.; Zhang, H.; Alvarez, A.; Evans, J.; Myerson, A. S.; Trout, B. L. Continuous Crystallization of Aliskiren Hemifumarate. Cryst. Growth Des. 2012, 12, 3036-3044.

(10) Hou, G.; Power, G.; Barrett, M.; Glennon, B.; Morris, G.; Zhao, Y. Development and Characterization of a Single Stage Mixed-Suspension, Mixed-Product-Removal Crystallization Process with a Novel Transfer Unit. Cryst. Growth Des. 2014, 14, 1782- 
1793.

(11) Power, G.; Hou, G.; Kamaraju, V. K.; Morris, G.; Zhao, Y.; Glennon, B. Design and Optimization of a Multistage Continuous Cooling Mixed Suspension, Mixed Product Removal Crystallizer. Chem. Eng. Sci. 2015, 133, 125-139.

(12) Lai, T. C.; Ferguson, S.; Palmer, L.; Trout, B. L.; Myerson, A. S. Continuous Crystallization and Polymorph Dynamics in the L - Glutamic Acid System. Org. Process Res. Dev. 2014, 18, 1382-1390.

(13) Lai, T. C.; Cornevin, J.; Ferguson, S.; Li, N.; Trout, B. L.; Myerson, A. S. Control of Polymorphism in Continuous Crystallization via Mixed Suspension Mixed Product Removal Systems Cascade Design. Cryst. Growth Des. 2015, 15, 3374-3382.

(14) Vartak, S.; Myerson, A. S. Continuous Crystallization with Impurity Complexation and Nanofiltration Recycle. Org. Process Res. Dev. 2017, 21, 253-261.

(15) Vetter, T.; Burcham, C. L.; Doherty, M. F. Regions of Attainable Particle Sizes in Continuous and Batch Crystallization Processes. Chem. Eng. Sci. 2014, 106, 167-180.

(16) Wang, X. Z.; Roberts, K. J.; Ma, C. Crystal Growth Measurement Using 2D and 3D Imaging and the Perspectives for Shape Control. Chem. Eng. Sci. 2008, 63, 1173-1184.

(17) Nagy, Z. K.; Braatz, R. D. Advances and New Directions in Crystallization Control. Annu. Rev. Chem. Biomol. Eng. 2012, 3, 55-75.

(18) Jiang, M.; Zhu, X.; Molaro, M. C.; Rasche, M. L.; Zhang, H.; Chadwick, K.; Raimondo, D. M.; Kim, K. K.; Zhou, L.; Zhu, Z.; et al. Modification of Crystal Shape through Deep 
Temperature Cycling. Ind. Eng. Chem. Res. 2014, 53, 5325-5336.

(19) Ferguson, S.; Morris, G.; Hao, H.; Barrett, M.; Glennon, B. In-Situ Monitoring and Characterization of Plug Flow Crystallizers. Chem. Eng. Sci. 2012, 77, 105-111.

(20) Luo, Y. H.; Wu, G. G.; Sun, B. W. Antisolvent Crystallization of Biapenem: Estimation of Growth and Nucleation Kinetics. J. Chem. Eng. Data 2013, 58, 588-597.

(21) Powell, K. a.; Saleemi, A. N.; Rielly, C. D.; Nagy, Z. K. Periodic Steady-State Flow Crystallization of a Pharmaceutical Drug Using MSMPR Operation. Chem. Eng. Process. Process Intensif. 2015, 97, 195-212.

(22) Leyssens, T.; Baudry, C.; Escudero Hernandez, M. L. Optimization of a Crystallization by Online FBRM Analysis of Needle-Shaped Crystals. Org. Process Res. Dev. 2011, 15, $413-426$.

(23) Powell, K. A.; Saleemi, A. N.; Rielly, C. D.; Nagy, Z. K. Monitoring Continuous Crystallization of Paracetamol in the Presence of an Additive Using an Integrated PAT Array and Multivariate Methods. Org. Process Res. Dev. 2016, 20, 626-636.

(24) Kutluay, S.; Sahin, Ö.; Ceyhan, A. A.; Izgi, M. S. Design and Optimization of Production Parameters for Boric Acid Crystals with the Crystallization Process in an MSMPR Crystallizer Using FBRM and PVM Technologies. J. Cryst. Growth 2017, 467, 172-180.

(25) O’Sullivan, B.; Barrett, P.; Hsiao, G.; Carr, A.; Glennon, B. In Situ Monitoring of Polymorphic Transitions. Org. Process Res. Dev. 2003, 7, 977-982.

(26) O'Sullivan, B.; Glennon, B. Application of in Situ FBRM and ATR-FTIR to the 
Monitoring of the Polymorphic Transformation of D-Mannitol. Org. Process Res. Dev. 2005, 9, 884-889.

(27) Schöll, J.; Bonalumi, D.; Vicum, L.; Mazzotti, M.; Müller, M. In Situ Monitoring and Modeling of the Solvent-Mediated Polymorphic Transformation of L -Glutamic Acid. Cryst. Growth Des. 2006, 6, 881-891.

(28) Calderon De Anda, J.; Wang, X. Z.; Lai, X.; Roberts, K. J.; Jennings, K. H.; Wilkinson, M. J.; Watson, D.; Roberts, D. Real-Time Product Morphology Monitoring in Crystallization Using Imaging Technique. AIChE J. 2005, 51, 1406-1414.

(29) Zhang, R.; Ma, C. Y.; Liu, J. J.; Wang, X. Z. On-Line Measurement of the Real Size and Shape of Crystals in Stirred Tank Crystalliser Using Non-Invasive Stereo Vision Imaging. Chem. Eng. Sci. 2015, 137, 9-21.

(30) Huo, Y.; Liu, T.; Liu, H.; Ma, C. Y.; Wang, X. Z. In-Situ Crystal Morphology Identification Using Imaging Analysis with Application to the L-Glutamic Acid Crystallization. Chem. Eng. Sci. 2016, 148, 126-139.

(31) Liu, T.; Huo, Y.; Ma, C. Y.; Wang, X. Z. Sparsity-Based Image Monitoring of Crystal Size Distribution during Crystallization. J. Cryst. Growth 2016, 469, 160-167.

(32) Eggers, J.; Kempkes, M.; Mazzotti, M. Measurement of Size and Shape Distributions of Particles through Image Analysis. Chem. Eng. Sci. 2008, 63, 5513-5521.

(33) Schorsch, S.; Vetter, T.; Mazzotti, M. Measuring Multidimensional Particle Size Distributions during Crystallization. Chem. Eng. Sci. 2012, 77, 130-142. 
(34) Schorsch, S.; Ochsenbein, D. R.; Vetter, T.; Morari, M.; Mazzotti, M. High Accuracy Online Measurement of Multidimensional Particle Size Distributions during Crystallization. Chem. Eng. Sci. 2014, 105, 155-168.

(35) Ma, C. Y.; Wang, X. Z. Crystal Growth Rate Dispersion Modeling Using Morphological Population Balance. AIChE J. 2008, 54, 2321-2334.

(36) Liang, Z.; Zhang, M.; Wu, F.; Chen, J. F.; Xue, C.; Zhao, H. Supersaturation Controlled Morphology and Aspect Ratio Changes of Benzoic Acid Crystals. Comput. Chem. Eng. 2017, 99, 296-303.

(37) Sha, Z. L.; Hatakka, H.; Louhi-Kultanen, M.; Palosaari, S. Crystallization Kinetics of Potassium Sulfate in an MSMPR Stirred Crystallizer. Journal of Crystal Growth. 1996, $166,1105-1110$.

(38) Puel, F.; Marchal, P.; Klein, J. Habit Transient Analysis in Industrial Crystallization Using Two Dimensional Crystal Sizing Technique. Chem. Eng. Res. Des. 1997, 75, 193-205.

(39) Toyokura, K.; Ohki, K. Size Distribution of Needle Crystals of Urea Obtained from an MSMPR Crystallizer.pdf. Int. Chem. Eng. 1991, 31, 493-500.

(40) Pons, M.-N.; Vivier, H.; Delcour, V.; Authelin, J.-R.; Paillères-Hubert, L. Morphological Analysis of Pharmaceutical Powders. Powder Technol. 2002, 128, 276-286.

(41) Kempkes, M.; Vetter, T.; Mazzotti, M. Monitoring the Particle Size and Shape in the Crystallization of Paracetamol from Water. Chem. Eng. Res. Des. 2010, 88, 447-454.

(42) Ferguson, S.; Morris, G.; Hao, H.; Barrett, M.; Glennon, B. Characterization of the Anti- 
Solvent Batch, Plug Flow and MSMPR Crystallization of Benzoic Acid. Chem. Eng. Sci. 2013, 104, 44-54.

(43) Borchert, C.; Temmel, E.; Eisenschmidt, H.; Lorenz, H.; Seidel-morgenstern, A.; Sundmacher, K. Image-Based in Situ Identification of Face Specific Crystal Growth Rates from Crystal Populations. Cryst. Growth Des. 2014, 14, 952-971.

(44) Myerson, A. S. Handbook of Industrial Crystallization, Second Edi.; ButterworthHeinemann, 2002.

(45) Randolph, A. D.; Larson, M. A. Theory of Particulate Processes - Analysis and Techniques of Continuous Crystallization; Academic Press, Inc., 1971.

(46) Morris, G.; Power, G.; Ferguson, S.; Barrett, M.; Hou, G.; Glennon, B. Estimation of Nucleation and Growth Kinetics of Benzoic Acid by Population Balance Modeling of a Continuous Cooling Mixed Suspension, Mixed Product Removal Crystallizer. Org. Process Res. Dev. 2015, 19, 1891-1902. 


\section{FOR TABLE OF CONTENTS USE ONLY}

\section{Characterization of a Multistage Continuous MSMPR Crystallization Process assisted by} Image Analysis of Elongated Crystals

Authors: Capellades, Gerard; Joshi, Parth; Dam-Johansen, Kim; Mealy, Michael; Christensen, Troels; Kiil, Søren.

Table of contents graphic:
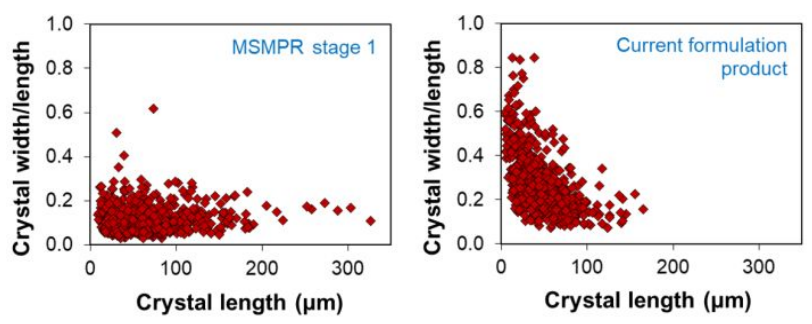

\section{Synopsis:}

A two-stage continuous crystallization process for a relevant pharmaceutical is presented and characterized based on quantitative image analysis of the crystallization magma. In a system where fragile elongated crystals are produced, the crystallization process has been optimized based on the most relevant crystal dimensions for the formulated product. 